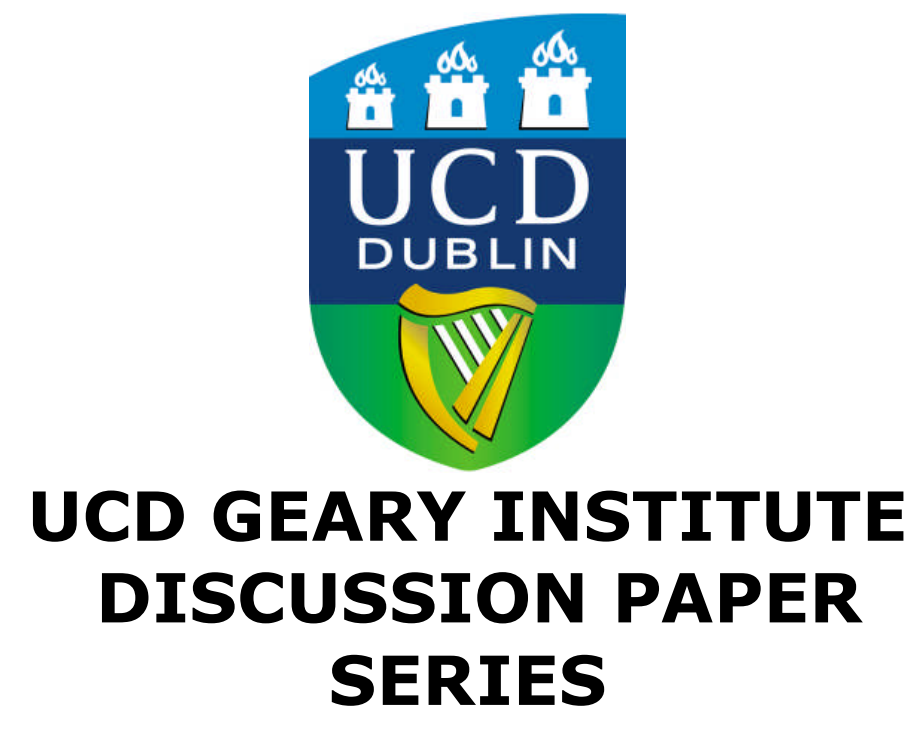

Caught in the Trap?

The Disincentive Effect of Social

Assistance

June 2009 


\title{
Caught in the Trap? \\ The Disincentive Effect of Social Assistance*
}

\author{
Olivier Bargain and Karina Doorley
}

July 2009

\begin{abstract}
While financial incentives usually have a significant effect on the labor supply of married women and single mothers, the evidence about the participation elasticity of childless singles, and single males especially, is more scant. This is, however, important in countries like France and Germany, where single individuals constitute the core of social assistance recipients. As yet, there is no conclusive evidence about whether, and to what extent, this group is affected by the financial disincentives embedded in the generous redistributive programs in place in these countries. In this paper, we exploit a particular feature of the main welfare scheme in France (Revenu Minimum d'Insertion, RMI), namely that childless adults under age 25 are not eligible for it. Using a regression discontinuity approach and the French micro-census data, we find that the RMI reduces the employment of uneducated single men by $7 \%-10 \%$. Important policy implications are drawn.
\end{abstract}

Key Words : Regression discontinuity; Welfare; Social assistance; Labor supply.

JEL Classification : H52; J21

\footnotetext{
*Acknowledgement: Bargain is affiliated to University College Dublin (UCD), IZA, the Geary Institute and CHILD; Doorley is affiliated to UCD and CEPS-INSTEAD. Doorley is grateful to the Irish Research Council for the Humanities and Social Sciences and to the Fonds national de la Recherche (Luxembourg) for financial support. The authors are indebted to participants to seminars at IZA, UCD and CEPS-INSTEAD for invaluable advice and comments. Usual disclaimers apply. Correspondence: Olivier Bargain, UCD, Newman Building, Dublin 4, Ireland. Phone: +35317168357. Email: olivier.bargain@ucd.ie
} 


\section{Introduction}

Welfare systems and labor market policies in continental Europe have compared unfavorably to their counterparts in the UK and the US with respect to their labor markets' performance. In particular, a set of generous redistributive schemes (and often a lack of activation policies) have often been blamed for contributing to persistent unemployment in France and Germany especially (cf., Laroque and Salanié, 2002). The French guaranteed minimum income, Revenu Minimum d'Insertion (RMI), is maybe one of the most representative schemes in this respect. The RMI was implemented in 1989 in response to mass unemployment and increased poverty in France. Designed as an income maintenance program to any adult citizen above 24 falling into poverty, it is time-unlimited and practically unconditional on any job search criteria or training. Beneficiaries are usually in a position to work, in contrast to the disabled or the elderly who receive other specific transfers. The number of "RMIsts" quickly expanded after its introduction and has oscillated around the one million mark since 1999 (cf. figure 6 in the Appendix). The scheme currently concerns more than three million people when dependent relatives of the recipients are accounted for. The RMI has thus quickly become a permanent form of income replacement for those who cannot qualify for the traditional unemployment insurance schemes, either because their contribution spells are too short or because they have exhausted their rights to these schemes. While there is no doubt that the RMI has a very large anti-poverty impact, it has also been accused of generating inactivity traps by dramatically reducing the gains to work for low-wage families (cf., Bourguignon, 1997).

Yet the extent or even the existence of this phenomenon has yet to be conclusively proven. In the empirical literature, most of the evidence for the potential disincentive effect of the RMI has been provided through estimations of structural labor supply models along with wage estimations. Laroque and Salanié (2002) find significant labor supply elasticities and potential disincentive effects amongst married women and single mothers. Gurgand and Margolis (2008) estimate monetary incentives for a representative sample of RMIsts. Although they find that potential gains to work are small on average, the conclusions of their study tend to minimize the inactivity trap explanation, except for single mothers. Notably in the French context, evaluation based on structural models has rarely been validated against experimental or quasi-experimental approaches. The main difficulty was the lack of a radical change in the RMI structure that could be exploited. ${ }^{1}$ The only natural experiment we are aware of concerns the Allocation Parentale d'Education, a replacement income for mothers of at least two children. Exploiting the extension of this scheme, Piketty $(1997,1998)$ find a relatively elastic female labor supply, reinforcing the view that disincentive effects are potentially large for this demographic group.

\footnotetext{
${ }^{1}$ The elasticity of transition into employment has been extensively studied in other countries. For instance in the US, Eissa and Liebman (1996) and Liebman (1996) used the large extensions of the Earned Income Tax Credit (EITC) in the late 1980s and early 1990s as a natural experiment. These reforms of the EITC made work more financially attractive for those with at least two dependent children. The authors find a significant increase in the employment rate for this group compared to others. In terms of experimentation, the most convincing attempt has to be the Canadian Self-Sufficieny Project (cf., Card and Robbins, 1996).
} 
Whether single men, who make up the core group of RMI recipients in France, are also concerned by labor supply effects remains to be seen. ${ }^{2}$ In this paper, we suggest a strategy for analyzing the potential disincentive effect of the RMI on employment among this group. We exploit an interesting feature of the scheme, namely the fact that childless adults under age 25 are not eligible for the RMI. This threshold provides a natural setting for analyzing the impact of the program using a regression discontinuity (RD) approach. The technique does not consist of studying a change of policy over time but a break in the existing policy at age 25. This means that, contrary to natural experiments, the evaluation is not muddled up by simultaneous changes in other policies or the economic environment. Thus, under the condition that agents cannot manipulate the 'forcing variable', RD estimates are as credible as those from a randomized experiment since assignment to treatment is as 'good as random' in the neighborhood of the discontinuity (see Hahn et al., 2001, Lee, 2008, Lee and Lemieux, 2009).

Our demonstration proceeds in three steps. In section 2, we first calculate financial returns to work for different educational levels and show that junior school dropouts should be the primary group of interest. Then we use the French Labor Force Survey (LFS) to investigate the employment trends over time and the take-up pattern of the RMI at different age levels. We obtain preliminary evidence that transition from employment to RMI occurs more frequently at age 25 than at any other age. The third and main part of our analysis is an application of the RD approach to the 1999 French census by exploiting the sharp discontinuity in the RMI scheme. We find convincing evidence that the RMI reduces the employment rate among uneducated single men at age 25. Interestingly, groups not affected by the threshold at this age (e.g., lone parents, uneducated men observed prior to the introduction of the RMI) and those less likely to respond to the treatment (high-education groups) do not show any effect.

The implications of these findings are potentially important for researchers and policy analysts. First of all, our results are in line with those of Lemieux and Milligan (2008) who exploit a similar feature of the Canadian system. ${ }^{3}$ The main difference is that we check here the effect of the entire scheme on labor market outcomes rather than a change in the generosity of the transfer. Therefore we can attempt to quantify (at least locally) the size of the inactivity trap generated by the RMI program. Secondly, the effect is significant for a specific group - junior school dropouts - but not for young adults with at least some education. Such identification of the group at risk potentially has important policy implications. Finally, from a broader perspective, the paper contributes to the (sparse) literature on male labor supply at the extensive margin. Interestingly, our findings confirm the results of structural estimations that point to higher employment elasticities among unskilled men (Aaberge et al. 1999, and Meghir and Phillips,

\footnotetext{
${ }^{2}$ In the labor supply literature, income and wage elasticities of hours are close to zero for men (see the survey of Blundell and MaCurdy, 1999). Men usually work full time so the interesting margin is participation. Yet, there is little evidence about participation elasticities for males, especially singles, in the literature (see the recent overview by Meghir and Phillips, 2008).

${ }^{3}$ The authors exploit the fact that before 1989, childless recipients under 30 years of age in Quebec received much lower benefits than recipients over the age of 30. They find strong evidence that more generous transfers reduce employment. Fortin et al. (2004) have also studied the effect of the 1989 change in benefits levels on welfare duration of various groups of single claimants. For France, Terracol (2008) studies the impact of the RMI on the hazard rate out of unemployment.
} 
2008). As argued above, this is all the more important as this group constitutes the majority of social assistance recipients in countries like France.

\section{Describing the Potential Inactivity Trap}

\subsection{Social Assistance in France}

The French guaranteed minimum income (RMI) is paid at the household level and complements the total net resources of the household, denoted $Y$, up to a maximum level $B(n)$ which depends on household size $n$ according to an explicit equivalence scale, as per table 1 . That is, the RMI paid is equal to $\max (0, B(n)-Y))$. Resources $Y$ include all incomes of all household members, net of taxes and social security contributions as well as all other social and family benefits received by the household, with the exception of housing subsidies. The latter are introduced as a lump-sum amount that depends on household characteristics and represents between $12 \%$ and $17 \%$ of the maximum RMI amount $B(n)$.

Table 1 shows that the redistributive effect of the scheme is potentially large, lifting people with no resources up to a level close to the official poverty line. Yet the differential nature of the RMI generates a $100 \%$ implicit marginal tax rate on earnings up to $B(n) .{ }^{4}$ The RMI can be claimed by anyone resident in France, at least 25 years of age and not in education. Importantly, the age condition does not apply to those in charge of dependent children living in the household. In addition to the transfer itself, a RMI recipient is automatically entitled to additional benefits, including a full exemption from the local residence tax (Taxe d'Habitation), access to free universal healthcare insurance (Couverture Médicale Universelle) and lower fares on public transport. Although entitlement to RMI is in principle conditional on an "integration" contract (Contrat d'Insertion), in practice it does not include any obligation to actively seek work.

The French welfare system is structured in such a way that the RMI acts as a last resort benefit for those who are ineligible for other schemes. The unemployed workers who have made sufficient contributions can receive unemployment benefits (UB) upon losing their job. After exhausting their entitlement to the UB, they are entitled to a means-tested social benefit (Allocation de Solidarité Spécifique, ASS) for two years under certain conditions. Specific minimum income schemes exist for disabled workers (Allocation aux Adultes Handicapés) and pensioners (Minimum vieillesse). For lone parents, a specific minimum income is available for one year or until the last child reaches the age of three (Allocation de Parent Isolé, API). The API is calculated in the same way as the RMI but the maximum theoretical amount is slightly larger. The RMI covers all other situations, including those who have exhausted their right to other benefits. The RMI is often complemented by means-tested housing subsidies, which can

\footnotetext{
${ }^{4}$ Note however that with the intéressement measures introduced in 1997, a RMI beneficiary can partly cumulate earnings and the RMI for some time. Precisely, the implicit marginal tax rate is reduced to $50 \%$ for the first 750 hours worked (see Hagneré and Trannoy, 2001, for a thorough assessment). Note that in 1999, the main year of interest in the rest of our study, the intéressement measure concerned only a limited number of RMI recipients. According to the LFS, only $8 \%$ of all RMI recipients were simultaneously recipients and employed.
} 
represent up to a third of the total transfer to those living purely on welfare. These benefits have different schedules that depend on the rent or the interest paid, the size of the dwelling, taxable income and the number of children in the household.

The interesting feature of the French system for the purpose of this paper is the fact that under the age of 25 , childless individuals who are able to work are not entitled to social assistance payments, with the exception of housing subsidies. The availability of the RMI at age 25 thus represents an important shock to the budget constraint as illustrated below.

Table 1: Maximum Amounts of RMI

\begin{tabular}{|c|c|c|c|c|}
\hline & No of children & $\begin{array}{l}\text { Maximum RMI } \\
\text { (EUR/month) }\end{array}$ & $\begin{array}{l}\text { Disp. income at } 0 \\
\text { earnings } \\
\text { (EUR/month)* }\end{array}$ & $\begin{array}{l}\text { Equiv. disp. Income } \\
\text { in } \% \text { of poverty } \\
\text { line }\end{array}$ \\
\hline \multirow[t]{4}{*}{ Single household } & 0 & 454 & 704 & 0.91 \\
\hline & 1 & 682 & 943 & 0.93 \\
\hline & 2 & 818 & 1,090 & 0.88 \\
\hline & per extra child & 182 & 192 & \\
\hline \multirow[t]{4}{*}{ Couple bousebold } & 0 & 682 & 995 & 0.85 \\
\hline & 1 & 818 & 1,178 & 0.84 \\
\hline & 2 & 955 & 1,341 & 0.82 \\
\hline & per extra child & 182 & 192 & \\
\hline
\end{tabular}

\subsection{Budget Constraints}

Figure 1 depicts budget constraints for single individuals with high and low education levels. Disposable income is computed on the basis of gross income (weekly hours times wage rate) and household characteristics, using a tax-benefit microsimulation model to calculate all direct taxes, social contributions and transfers. We use the median wage for each education group as drawn from a sample of single men aged 20-35 taken from the Labor Force Survey (cf., first row of table 7 in the Appendix). The first type corresponds to the lowest education level, referred to as "junior school dropout" in what follows. $^{5}$ The second type is a college-educated person. The graph starts with a horizontal plateau that corresponds to welfare payments (RMI and housing subsidies) and that characterizes the inactivity trap. Beyond this zone, the slope is increasing and becomes steeper for higher wage/education levels. Adding an indifference curve to the graph clearly illustrates that different productivities lead to contrasting labor

\footnotetext{
${ }^{5}$ In France, education is compulsory until age 16. This age normally corresponds to the end of the first cycle of highschool, which is examined with the Diplôme National du Brevet. In practice, students who have repeated one or several years of school and reach age 16 before sitting this exam may leave school. "Junior school dropouts" are those who do not pass the Brevet and quit the education system without any diploma (they hold a Certificat d'Etudes Primaires). They are essentially comparable to High School dropouts in the US.
} 
supply choices. All else equal (and in particular preferences), the uneducated worker is induced to leave the labor market upon becoming eligible for the RMI at age 25 while a college-educated person will work (around 35 hours per week in our example). Before 25, the junior school dropout receives only housing subsidies at zero hours (point A); a similar individual aged 25 attains a level of disposable income $162 \%$ higher thanks to the RMI (point B).

To get a better idea of the potential disincentive effect at the extensive margin, we calculate the relative gains to work. This is defined as the percentage increase in disposable income upon moving from inactivity (and receiving the RMI) to part/full time work. This calculation is performed for single men aged 20-35 at different education levels, as reported in table 7 in the Appendix. It turns out that for junior school dropouts, the median relative gain is close to zero for a part-time job. It is larger for a full-time job (just over 60\%) but this only corresponds to an additional EUR 370 per month, which may be partly reduced by costs of work (e.g., transportation costs). The gains become more significant with higher educational attainment. ${ }^{6}$ These results indicate clearly that when the 25 year old mark has been passed, people may react very differently to the treatment "availability of the RMI" depending on their potential returns on the labor market. Table 7 also shows the distribution of single men according to educational attainment and compares it to the distribution of those receiving the RMI. It is clear that junior school dropouts are over-represented among RMI recipients (52\%) compared to the overall population $(22 \%)$. All of the other groups are proportionally under-represented. The group of junior school dropouts appears to be most at risk of succumbing to the inactivity trap and is therefore the focus of our attention in the rest of the paper.

Interestingly, the $\mathrm{RD}$ approach suggested in this paper provides an informal test of the two predictions made by the static labor supply model in figure 1 . First, individuals with very low potential wages should drop out of the labor market once they reach age 25 and become eligible for the RMI. Second, the adjustment should take place at the extensive (participation) margin as opposed to the intensive margin (hours of work conditional on participating). Quite clearly, however, such a simple model imposes strong restrictions on rationality. Even in a static framework, it is possible to explain why some people work despite small (or negative) financial gains. In particular, work (or at least the first hours of work) may provide some well-being through social inclusion while inactivity may carry specific disutility due to the stigma of living on welfare assistance. It is also possible to depart from the assumption of static rationality made in most policy evaluations (e.g., Blundell et al., 2000). ${ }^{7}$ In what follows, we attempt to quantify

\footnotetext{
${ }^{6}$ Other groups include those people who opt for a two-year apprenticeship (Certificat d'Aptitude Professionnelle and Brevet d'Etudes Professionnelles), those who complete highschool and students who pursue college or higher university education.

${ }^{7}$ If agents are forward-looking, they will anticipate human capital accumulation and higher future wages. Yet there is no clear evidence that they do so (see Meghir and Phillips, 2008, for a recent survey on dynamic labor supply estimations) or that future wage prospects are high enough. Guillemot et al. (2002) argue that dynamic aspects may not be very relevant; they report that RMIsts who re-enter the labor market are usually in precarious situations, holding subsidized and timelimited jobs and having a higher chance of becoming unemployed the following year. To refute the existence of inactivity traps, these authors favor static explanations in terms of the social effect of work and stigma attached to assistance.
} 


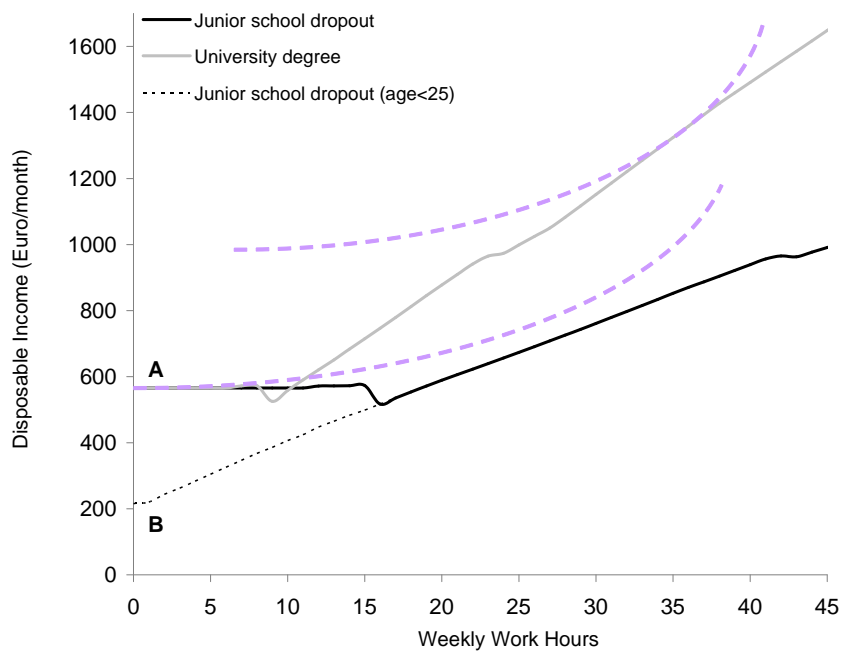

Sources: budget constraints of childless single individuals, simulated using the microsimulation model SYSIFF and taking the mean wage of each educational group as basis for the simulations (mean value obtained from the Labor Force Survey).

Figure 1: Representative Budget Constraints

the number of workers for whom financial disincentives are strong enough - or the taste for work, stigma and intertemporal substitution effects are small enough - to generate negative employment effects.

\section{Data and Selection}

\section{Labor Force Survey}

The first dataset we use is the French Labor Force Survey (LFS), which was conducted on an annual basis for the periods 1982-1989 and 1990-2002 by the French Statistical Office (Institut de la Statistique et des Etudes Economiques, INSEE). For cross-sectional use, the annual LFS is a large representative sample of the French population aged 15 or over (sampling rate: 1/300). It provides information on employment, incomes, education and demographics. The LFS is also a rotating panel: each household remains in the survey for three consecutive years with one third being replaced each year. In the next section, we use the LFS primarily to document the long-term trends in the labor market behavior of our target population. We also use the panel dimension to describe movements into RMI at different age levels.

\section{Census data}

The RD analysis is based on the French census data, which is publicly available from INSEE. The coverage of the census is universal. Two sizes of dataset are available. Since the RD approach requires a large sample size, we opt for the larger census which samples one quarter of the population (around 14.5 million people). The sample provides data on age (in day), employment, type of contract, work duration, 
marital status and household type. ${ }^{8}$ We use the 1999 census data in our main RD estimations, that is, ten years after the implementation of the RMI. We shall also use the 1982 census data as a control group hereafter.

For the main RD analysis, we focus on single men without children. Most importantly, (childless) single individuals represent the main group of claimants, i.e., around $58 \%$ of all RMIsts. ${ }^{9}$ Another reason for this choice is that the joint labor supply decision in couples is more complicated and does not provide as clear evidence as with singles. The selection of individuals without children is obviously due to the fact that a parent is eligible for the RMI regardless of his/her age. ${ }^{10}$ However, we carefully investigate the possible selection bias implied by focusing on childless single men and replicate the RD analysis for a broader group of men hereafter. The selection on males is motivated by the fact that a larger fraction of women have children at age 25 and hence are not subject to the age restriction. ${ }^{11}$ Moreover, women are more at risk of being affected by the possible selection bias engendered by choosing only childless persons; they are also more concerned by potential fertility responses to financial incentives. We discuss these and other possible manipulation effects in detail below.

As justified in the previous section, junior school dropouts constitute our target group as they are the most at risk of financial disincentives. With the quarter census, we can create cells of a sufficiently large size for robust analysis. Table 8 in the Appendix shows that there are more than 74,000 observations for each year of age. Junior school dropouts represent between $10 \%$ and $15 \%$ of all men, leading to cells of more than 4,000 observations per age group when childless singles are selected. Note also that we restrict our analysis to the group aged between $20-35$ for the main RD estimation results. Considering individuals under the age of 20 could lead to less robust results as we would encounter less and less people in each age cell. Not all junior school dropouts leave the education system at age 16 as some of them may repeat one or more years of school. ${ }^{12}$ The upper bound (35 years of age) is arbitrarily chosen but we perform sensitivity analysis on the age window in what follows.

\section{Social Assistance and Employment: Some Evidence using La- bor Force Surveys}

Before using the LFS, we rely on official statistics to describe the trends on the French labor market. Figure 6 in the Appendix illustrates the sharp increase in unemployment (ILO definition) in the 1990s,

\footnotetext{
${ }^{8}$ Data on income, past year employment and receipt/amount of RMI or other benefits is unfortunately not available.

${ }^{9}$ The population of RMI recipients is decomposed as follows: $38 \%$ are single men, $20 \%$ are single women, $13 \%$ are lone parents with one child, $12 \%$ are lone parents with more than one child and the rest are couples with or without children ( $13 \%$ and $4 \%$ respectively)

${ }^{10}$ We refer to people as 'childless' or 'without children' when they either do not have children or have children but do not live with them.

${ }^{11}$ In France, women have their children at a younger age than men. Women are also much more likely than men to be single parents.

${ }^{12}$ Importantly, note that our selection excludes all those who are still at school or in some form of education.
} 
accompanied by a dramatic increase in the number of people on welfare following the introduction of the RMI in 1989. Notice that only around a third of the RMI recipients are registered as job seekers and are hence accounted for in the ILO-defined unemployment figures.

The rapid expansion of the number of RMIsts in the first half of the 1990s reflects the downturn in the economic situation during this period but also the increased generosity of the scheme, which ensures that more people qualify, and the stricter rules governing unemployment insurance following its 1992-93 reform. The economic recovery of the 1997-2001 period is characterized by declining unemployment but this has not fully trickled down to the poorest levels. Effectively, while unemployment has returned to the level of the late 1980s, the number of RMIsts has declined with a delay and only temporarily. Many reasons have been invoked. On the demand side, the RMI status is negatively perceived by employers so that recipients are among the last to re-enter the labor market during upturns. On the supply side, it is possible that claiming behavior has changed due to lower participation costs, better information on the availability of the benefit or lower social stigma associated with the claim. ${ }^{13}$ This may in turn affect labor market participation as argued below.

Next, we use the LFS to graph the long-term trends in employment for single males around the discontinuity at age 25. A three-year moving average is used to smooth the series. Results are reported in figure 2, plotted by broad educational groups. The top two lines trace the employment rate for 20-24 year olds and 25-30 year olds with some education (vocational training, highschool or university education). These two groups follow the business cycle, with employment decreasing until the mid-1990s and picking up in the second half of the decade. Yet the younger group shows larger fluctuations, in particular falling more rapidly with the downturn of the early 1990s, and is always distinguished by a lower employment rate. This is in line with known results about the French labor market, and in particular the existence of a high universal minimum wage which encourages the exclusion of the youngest workers (see Abowd et al., 1999, Cahuc et al., 2008). ${ }^{14}$ The second set of lines shows the employment rate for junior school dropouts aged 20-24 and 25-30. These two age groups do not follow each other as closely as those with education do. The 25-30 year olds show a gradual decline in employment, in marked contrast to their younger counterparts who closely track the business cycle. This suggests that the availability of the RMI for the former age group has incited a labor supply response and resigned this group to a more permanent level of under-employment; this is especially the case during the 1990s period characterized by the continued expansion of the RMI. ${ }^{15}$

\footnotetext{
${ }^{13}$ Sociological studies point toward a self-reinforcing process whereby the number of claimants affects the perceived normality of the claim and the propensity to take-up in the following years (see Mood, 2004). See Terracol (2003) on the take-up of RMI in France.

${ }^{14}$ Young workers (outsiders) are judged less productive than the level at which the minimum wage is negotiated by other, older workers. As a result, France has one of the lowest employment rates of 20-24 year olds in the OECD (cf., Cahuc et al., 2008).

${ }^{15}$ Admittedly, this evidence is not concrete as there may be different responses to macroeconomic shocks for different age groups. If this was the case, however, we would expect it to happen for the two higher-educated age groups too. It clearly does not, which suggests that those with some education are much less affected by the RMI, as shall be demonstrated in the following RD analysis.
} 


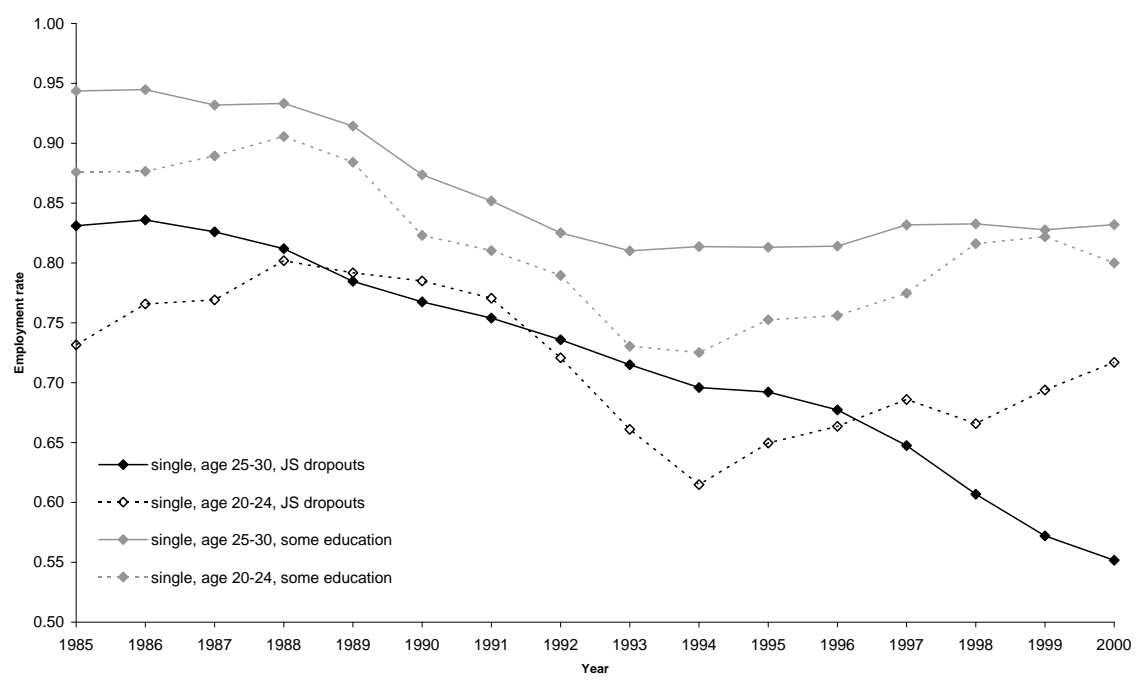

Figure 2: Employment Trends

Finally, we exploit the (rotating) panel dimension of the LFS 1990-2002 to track people who take up the RMI at some stage during their observation. We define "new RMIsts" as those observed as recipients in year $\mathrm{N}$ and not in year $\mathrm{N}-1 .{ }^{16}$ To keep the largest possible sample, we include men and women from all educational groups and family types. However, we only keep individuals who are observed at least twice and for whom we have complete information on employment and RMI status. This represents an attrition rate of $24 \%$ on average over the period 1990-2002.

We are interested in the relationship between age and movement into RMI as reported in figure 3. The first observation is that the number of RMIsts (as a \% of the active population of each age cell) reaches a peak at age $25-27$, then decreases gradually with age and is relatively stable after 35 . The over-representation of young workers among RMI recipients is the result of a number of factors including higher risk of unemployment and low UB coverage for this population. Furthermore, figure 3 shows that the proportion of "new RMIsts" (as a \% of all RMIsts in each age cell) is at its maximum at age $25,{ }^{17}$ then decreases sharply and oscillates between $30 \%$ and $40 \%$. As expected, an important fraction of the movers at age 25 were unemployed in the previous year, probably uncovered by UB and hence "waiting" for the RMI. Yet the bottom line of figure 3 shows that $12 \%$ of the new entries at age 25 were employed the year before. Importantly, this proportion decreases after 25 and stabilizes at around $7 \%$ of all recipients at each other age level. We interpret these results as follows: among the $12 \%$ at age 25, 7 percentage points (ppt) correspond to people affected by a recent unemployment shock and 5 points to

\footnotetext{
${ }^{16}$ Naturally, movements in and out of the RMI status may be more frequent, but the interval provided in the LFS panel does not allow thinner time decomposition. Note also that since we follow people for three years at most, each individual can be classified as a new RMIst at most once.

${ }^{17}$ It is around two third of all RMIsts, the remaining third corresponding to "old RMIsts", i.e., those with children who received the RMI under 25 .
} 
people who may have stopped working to take up the RMI at age 25. These results are suggestive but suffer from the small sample size of the LFS (sampling rate of 1/300) and the fact that RMI recipients are under-represented in the survey.

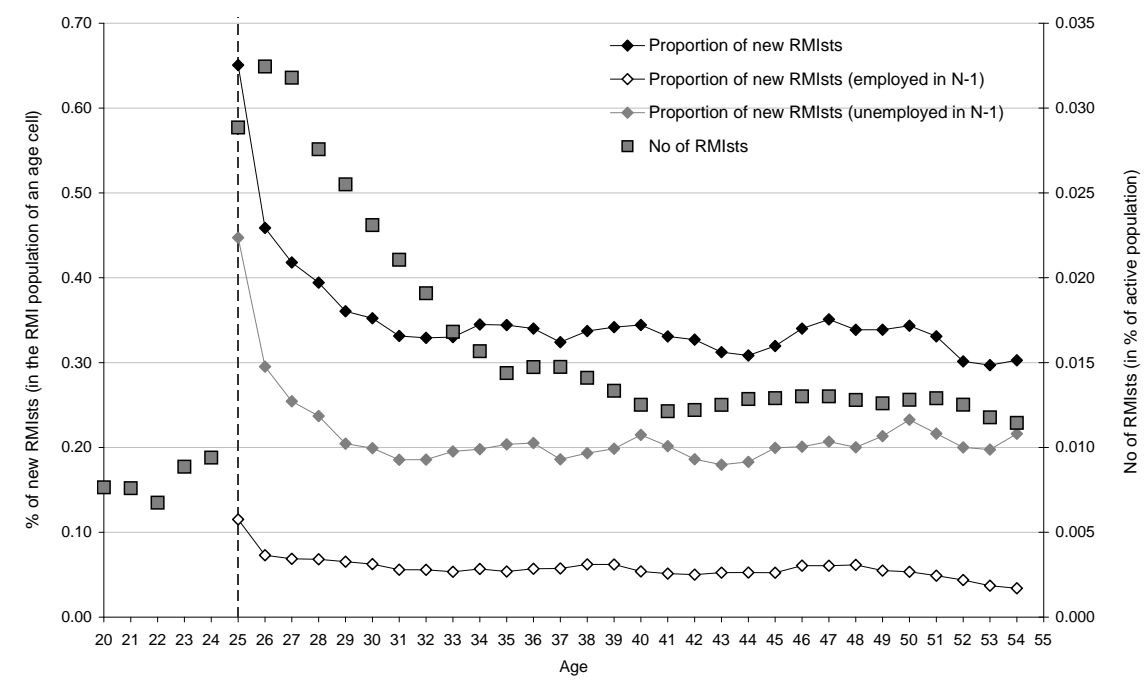

Figure 3: Proportion of "new" RMI Recipients

\section{A Regression Discontinuity Analysis}

\subsection{RMI, What Else?}

Before we turn to the RD design, we check that no significant discontinuity, other than the age break in the eligibility for the RMI, exists that could explain a negative employment effect at age 25 . We investigate three main areas: labor market regulations, the tax-benefit structure and parents' legal obligations to financially support their children.

Regarding the labor market, active labor market policies related to youth employment were in place in 1999, notably public employment schemes for low-skilled unemployed young adults (e.g., Contrat Emploi Solidarité, CES), newly introduced subsidized job schemes (Contrats Emplois Jeunes, launched in 1997) and private contracts associated with subsidized on-the-job training (e.g., Contrat de Qualification). However, the different schemes concerned young workers aged under 26 so that any break in employment figures would occur at 26 rather than 25. Another important policy concerns payroll tax subsidies for minimum wage workers but these subsidies are defined according to wage rate levels and make no reference to age. All of these measures and their employment effects are described in Fougère et al. (2000).

Examining the tax-benefit system, the only important issue that emerges is the possibility for parents to declare children as dependent in order to obtain tax deductions or benefit increments. Children can be 
treated as dependent only until age 21 in the benefit system. The only exception is the RMI itself, i.e., parents receiving the RMI obtain an increment for the presence of children aged 21-24; yet this applies only if the child is a student, and hence does not concern our target group of junior school dropouts. As for the tax system, tax deductions are linked to the legal obligation of parents to financially take care of their children until their 25th birthday. A possible consequence is the decrease in intra-family transfers in the direction of children when they reach 25 , accentuated by a decrease in total household income (as parents do no longer benefit from the increment of RMI, if recipients, or from the tax deduction, if tax payers). Clearly, this cannot explain a drop in employment at age 25. Admittedly, however, it may reduce the employment effect of the RMI as captured in what follows. Finally, a decrease in parental transfer and the possibility of taking up the RMI at age 25 may induce changes in living arrangements. However, we find no statistical evidence of a discontinuity in cohabitation rates with parents at age 25 . The proportion of cohabitants is reported in the last column of table 8 . Potential changes in living arrangements with partners and children receive specific attention in section 5.8 .

\subsection{Empirical Approach}

Using census data, we now exploit the discontinuity in the RMI scheme at age 25. Consider the regression model:

$$
Y_{i a}=\beta_{0}+\beta_{1} T R E A T_{i a}+\delta(a)+\varepsilon_{i a}
$$

where $Y_{i a}$ is an outcome variable for individual $i$ of age $a$. The main outcome we focus on hereafter is labor supply (either participation or hours of work). The effect of age (the forcing variable) on the outcome variable is captured by the function $\delta(a)$ while $T R E A T_{i a}$ is a treatment dummy that takes value 1 if the individual is aged 25 or above and zero otherwise. This way, we can estimate the effect $\beta_{1}$ of the treatment (the potential availability of the RMI) on the outcome variable. The key identification assumption of the $\mathrm{RD}$ approach is that $\delta(\cdot)$ is a continuous function. Under this assumption, the treatment effect $\beta_{1}$ is obtained by estimating the discontinuity in the empirical regression function at the point where the forcing variable switches from 0 to 1 (age 25 in our case). ${ }^{18}$

The main argument for assuming that $\delta(\cdot)$ is a smooth function is that labor supply variables typically exhibit regular age profiles. Function $\delta(\cdot)$ should certainly be flexible enough to accommodate nonlinearities in the age profiles, but there is no reason - in human capital or related theories of behavior over the lifecycle - to expect an abrupt change in labor supply at age 25. Moreover, we have argued that no other discontinuity embedded in redistributive or labor market policies could explain a negative employment effect at that particular age. Nevertheless, several robustness checks are provided in what follows. ${ }^{19}$ In particular, we shall investigate any bias due to the selection of single individuals without

\footnotetext{
${ }^{18}$ We would like to include additional control variables in our regressions but the target group is already homogenous in terms of education level and marital status. The region of residence could be added to proxy the local employment opportunities, but this information is not available in the $1 / 4$ selection of the Census data.

${ }^{19}$ We rule out the possibility that people "cheat" on their age, as this information is easily and systematically verified by
} 
dependent children. If fertility and living arrangements decisions are endogenous, the target group of our main analysis could indeed present a problem of non-random selection. The important point is to check whether the bias is itself is a smooth function of age. If it is, it will be accounted for by function $\delta(\cdot)$ and the $\mathrm{RD}$ approach remains valid.

Age is available in days so that we know exactly what age people are at census day and their employment status at that date. Consequently, and because the treatment variable (labor supply) is a deterministic function of the forcing variable (age), this is a "sharp" RD design.

We do not use age in days to perform the RD estimation for two reasons. Firstly, it is not clear when the potential labor supply response would occur after turning 25 . Individuals who were working before their 25th birthday may not be aware that the RMI is means-tested on the income earned during the three months prior to the claim. Secondly, age cells obtained when age is measured in days are too small for any meaningful analysis and would display a very erratic pattern. Rather, in order to reduce the amount of noise, our parametric analysis makes use of age in years and quarters. The problem is thus one where the forcing variable is discrete and all the information is summarized in the age-specific means of the variables, a situation extensively discussed in Lee and Card (2008). This way, estimates of equation (1) based on individual data are identical to estimates of the age-cell version of the model:

$$
Y_{a}=\beta_{0}+\beta_{1} \operatorname{TREAT} T_{a}+\delta(a)+\varepsilon_{a},
$$

weighted by the number of observations by age group.

In the discrete case, the treatment effect is not identified non-parametrically (cf. Lee and Card, 2008). Indeed, a discrete dependent variable means that we cannot compare observations "close enough" on both sides of the cutoff point to be able to identify the effect. Hence we rely on various parametric functions of the forcing variable $a$ in order to balance the usual trade-off between precision and bias. We use a variety of polynomial forms, including standard linear, quadratic, and cubic functions, as well as linear and quadratic splines (separate regressions on both sides of the discontinuity). Inconveniently, this approach provides global estimates of the regression function over all values of the forcing variable, while the RD design depends instead on local estimates of the regression function at the cutoff point. Thus we also present estimates of the linear spline model for an increasingly small window around age 25 as a further robustness check.

We use different measures to check how well the polynomial models fit the data. Denote $J$ the number of age years/quarters and $K$ the number of parameters estimated in function $\delta(\cdot)$. Since the outcome variable $Y_{a}$ is a cell mean, its sampling variance $V_{a}$ can be easily computed. Under the assumption that specification (2) is correct, the only source of error in the model should be the sampling error. This assumption can be tested using the goodness-of-fit statistic:

$$
G O F_{1}=\sum_{a}\left(\widehat{\varepsilon}_{a}^{2} / V_{a}\right) .
$$

benefit agencies. Nonetheless, the procedure of McCrary (2008) is applied below to test any possible manipulation of the forcing variable. 
Under the null hypothesis that model (2) is the true model, $G O F_{1}$ should follow a $\chi^{2}$ distribution with $J-K$ degrees of freedom. The fact that the forcing variable is discrete also provides a natural way of testing whether the regression model is well specified by comparing the fitted model to the raw dispersion in mean outcomes at each value of the variable. Lee and Card (2008) show that the specification can be tested using the statistic:

$$
G O F_{2}=\frac{\left(E S S_{R}-E S S_{U R}\right) /(J-K)}{E S S_{U R} /(N-J)}
$$

where $E S S_{R}$ is the estimated error sum of squares of the model (2) while $E S S_{U R}$ is the estimated error sum of squares of a model where a full set of dummy variables for the $J$ values of the forcing variable are included. In this unrestricted model, the fitted regression corresponds to the mean outcome in each cell. Under normality and heteroskedasticity of $\varepsilon_{a}, G O F_{2}$ follows a $F(J-K, N-J)$ distribution where $N$ is the number of observations. This is not a definitive test - Lee and Card note that rejection of a given polynomial form $\delta(\cdot)$ does not necessarily imply that the corresponding estimate of the effect is inconsistent - but confidence in a chosen specification increases if it cannot be rejected by this test. ${ }^{20}$

Complementary to the parametric approach, we treat age in months as continuous in order to perform nonparametric estimations. We use local linear regressions, advocated to reduce the bias inherent to nonparametric regressions at boundary points (Hahn et al., 2001). We have experimented with different types of kernel functions including the triangular kernel, known to be optimal for estimating local linear regressions at the boundary (Fan and Gijbels, 1996), and the rectangular kernel with various bandwidths. Using a variety of bandwidths is important in order to balance precision and bias. Standard errors are obtained by bootstrapping.

\subsection{Regression Discontinuity: Graphical Results}

Before looking at statistical results, we present graphical evidence of a drop in the conditional mean of the outcome at the 25 year-old threshold. As argued by Imbens and Lemieux (2008), the graphical representation of the discontinuity should be an integral part of any RD analysis. No evidence of that sort would cast serious doubt on the more sophisticated statistical analysis that follows.

We use the 1999 census to plot the raw employment rates by age, along with the $95 \%$ level confidence bounds, for single male junior school dropouts. For age in years, figure 4 suggests that employment drops sharply at age 25 , that is, when people become eligible for the RMI. Figure 5 presents the same result with age in quarters but displays slightly more noise due to smaller age cells. Both graphs confirm that the drop in the outcome variable at the cutoff is unusually large compared to other bumps in the curve away from the cutoff.

\footnotetext{
${ }^{20}$ Lee and Card (2008) also interpret the difference between the true conditional expectation and the estimated regression function (forming the basis of the $G O F_{2}$ test) as a random specification error that introduces a group structure into the standard errors. Correcting for group structure can be done by "clustering" standard errors in model (1) or simply by running the model on weighted cell means, i.e., model (2). The $G O F_{2}$ test can be interpreted as a test of whether standard errors should be adjusted for group structure.
} 
The steep upward trend in employment rates before the discontinuity is in line with the widely accepted theory that the employment rate is a concave function of age. In the French context, however, this also corresponds to the higher discrimination against the youngest workers, as discussed in the previous section. This pattern of increasing employment before 25 is also observed for other groups (e.g., lone mothers, cf. figure 8 in the Appendix, or broader male groups, cf. figure 11). The relatively flat trend observed for the segment 25-35 is driven by the nature of the group of interest, namely men without children. As demonstrated in section 5.9, these are negatively selected in terms of their labor market outcomes.

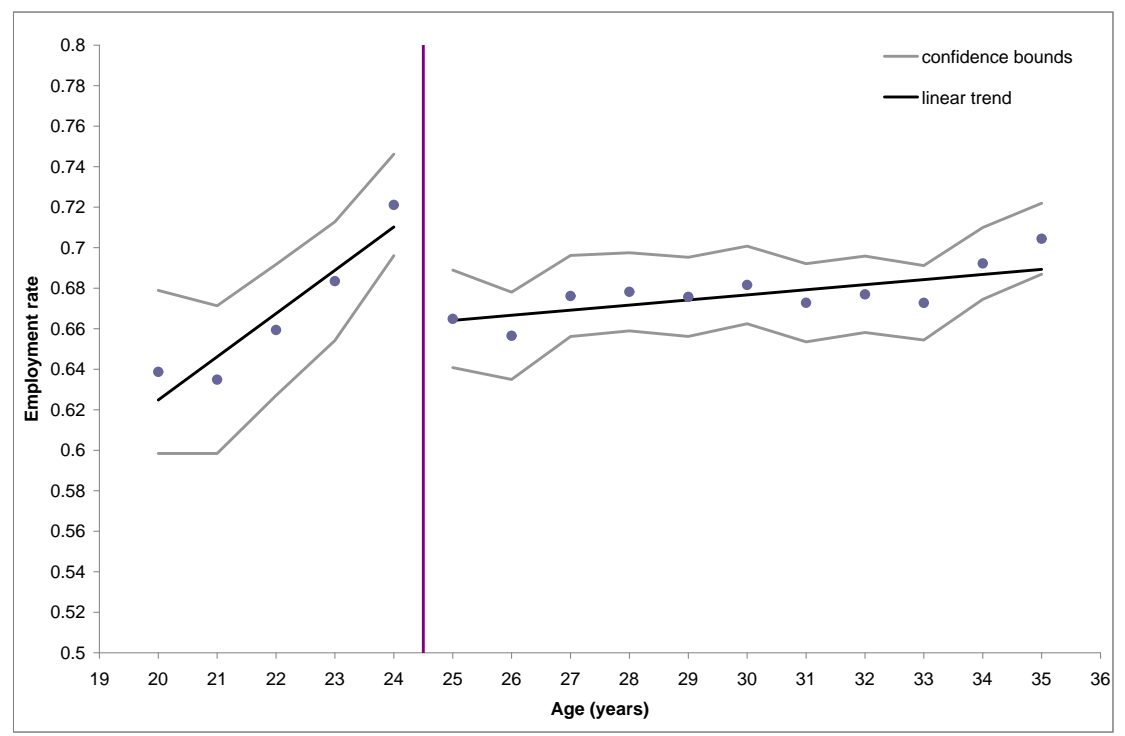

Figure 4: Employment Rate of Single Male JS Dropouts (Census 1999, Age in Years)

\subsection{Regression Discontinuity Estimates}

We now turn to the main regression results presented in table 2. We first focus on the estimated treatment effect on the employment rates of our group of interest in 1999, i.e., single male junior school dropouts aged 20-35. The employment impact is accurately estimated for all flexible specifications of $\delta(\cdot)$. The treatment is not significant when using the linear form, which may be too restrictive given the different slopes on each side of the discontinuity point in figure 4. The treatment effect is more precisely estimated with age in years but results are very similar when using either years or quarters. In ppt of the employment rate, all models give an effect of magnitude between -6.9 and -4.9 . When accounting for standard errors, these effects are not statistically different from one another. Effects expressed in ppt can be divided by the average employment rate $(68 \%)$ to give the proportion of people concerned by the disincentive effect at the discontinuity, i.e., between $7.2 \%$ and $10.2 \%$ of our selected target group. ${ }^{21}$

\footnotetext{
${ }^{21}$ Thus, since junior school dropouts represent around half of the RMIsts (cf., table 7), the inactivity trap roughly concern $5 \%$ of the RMI population at this age. This is the same order of magnitude as what we found in the panel analysis of the
} 


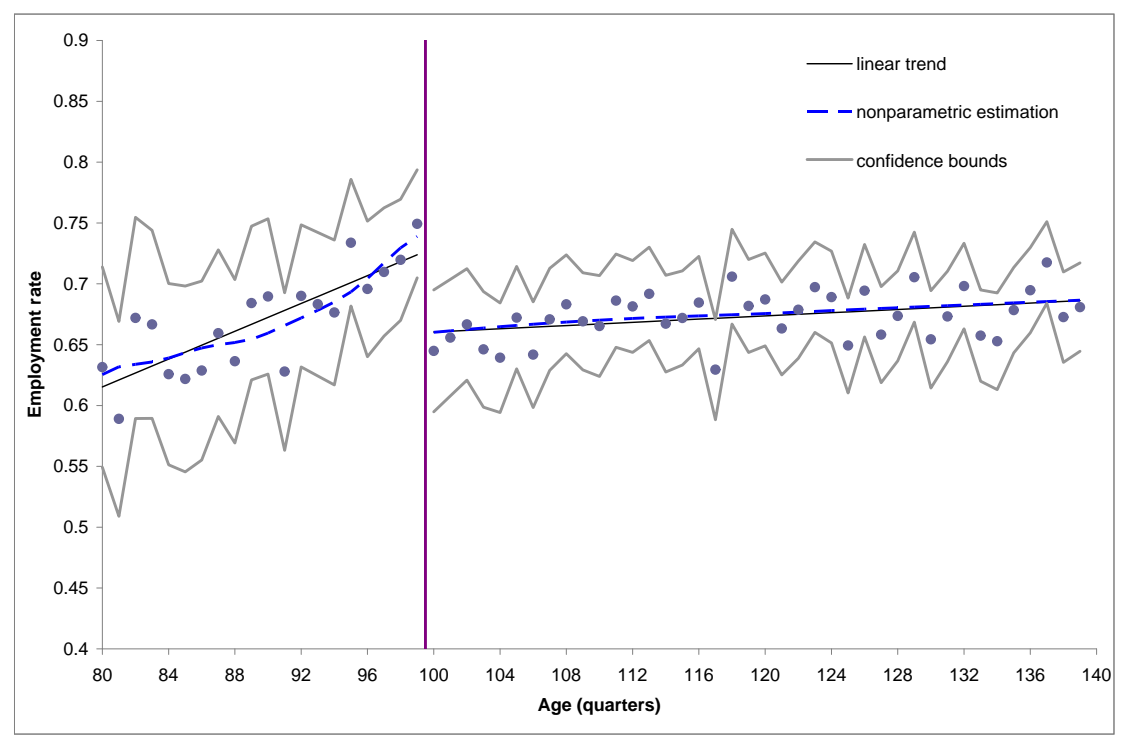

Figure 5: Employment Rate of Single Male JS Dropouts (Census 1999, Age in Quarters)

Goodness-of-fit measures suggest that all models fit the data very well; the two measures $G O F_{1}$ and $G O F_{2}$ actually lead to very similar results. In table 2, the p-values are reported for all flexible models and show that we cannot reject these models at reasonable significance levels.

The last two columns of table 2 report the treatment effect for another labor supply measure, namely the number of work hours at census week (including zeros). The effect of the RMI is significant for all the flexible measures and is located in the range $[-2.7,-1.9]$. This represents between $7.3 \%$ and $10.6 \%$ of the average hours of work (25.5), which is very similar to the aforementioned effect on employment probability. This suggests that all of the impact of the RMI on labor supply happens at the extensive margin, as predicted by the simple static labor supply model.

In addition to labor supply variables, we also exploit information on work contracts. Those who stop working at 25 may have unobserved characteristics that also lead to a weaker attachment to the labor market. Also, they may anticipate the possibility of living on welfare at 25 and provide minimum search effort, i.e., do not attempt to find long-term or tenured positions. If this is the case, we expect to see a drop in the proportion of short-term contracts among uneducated workers at age 25 . We find that this is indeed the case (detailed results are available upon request). For the estimations based on age in quarters, the treatment effect is significant for all specifications. When using age in years, the effect is significant for all specifications but the quadratic spline. The drop in the number of short-term contracts (in $\%$ of all contracts) is in a range between 2.3 and 4 ppt across the different specifications. We discuss the welfare implications and intertemporal aspects in the concluding section.

previous section. 
Table 2: RD Estimates of the Effect of RMI on Labor supply, Single Male JS Dropouts, 1999

\begin{tabular}{|c|c|c|c|c|}
\hline Mean of the dependent variable & \multicolumn{2}{|c|}{ Emp. Rate } & \multicolumn{2}{|c|}{ Weekly hours } \\
\hline & \multicolumn{2}{|c|}{0.68} & \multicolumn{2}{|c|}{25.5} \\
\hline Polynomial specification for age: & age in: years & quarters & years & quarters \\
\hline \multirow[t]{2}{*}{ Linear } & -0.027 & $-0.028 * *$ & -0.881 & -0.918 \\
\hline & $(0.018)$ & $(0.014)$ & $(0.773)$ & $(0.573)$ \\
\hline \multirow[t]{2}{*}{ Quadratic } & $-0.067 * * *$ & $-0.069 * * *$ & $-2.601 * * *$ & $-2.700 * * *$ \\
\hline & $(0.013)$ & $(0.015)$ & $(0.568)$ & $(0.622)$ \\
\hline \multirow[t]{2}{*}{ Cubic } & $-0.065 * * *$ & $-0.067 * * *$ & $-2.402 * * *$ & $-2.514 * * *$ \\
\hline & $(0.014)$ & $(0.016)$ & $(0.594)$ & $(0.654)$ \\
\hline \multirow[t]{2}{*}{ Linear spline } & $-0.049 * * *$ & $-0.058 * * *$ & $-1.874 * * *$ & $-2.300 * * *$ \\
\hline & $(0.010)$ & $(0.014)$ & $(0.365)$ & $(0.536)$ \\
\hline \multirow[t]{2}{*}{ Quadratic spline } & $-0.067 * * *$ & $-0.068 * * *$ & $-2.327 * * *$ & $-2.405 * * *$ \\
\hline & $(0.017)$ & $(0.018)$ & $(0.719)$ & $(0.740)$ \\
\hline \multicolumn{5}{|l|}{ Goodness of fit statistic 1 (p-value) } \\
\hline Quadratic & 0.92 & 0.75 & 0.78 & 0.55 \\
\hline Cubic & 0.88 & 0.73 & 0.78 & 0.55 \\
\hline Linear spline & 0.96 & 0.80 & 0.96 & 0.71 \\
\hline Quadratic spline & 0.81 & 0.68 & 0.65 & 0.50 \\
\hline \multicolumn{5}{|l|}{ Goodness of fit statistic 2 (p-value) } \\
\hline Quadratic & 0.98 & 0.80 & 0.88 & 0.61 \\
\hline Cubic & 0.97 & 0.77 & 0.89 & 0.60 \\
\hline Linear spline & 1.00 & 0.84 & 1.00 & 0.75 \\
\hline Quadratic spline & 0.92 & 0.73 & 0.77 & 0.55 \\
\hline
\end{tabular}

Note: statistical significance at the $1 \%, 5 \%, 10 \%$ levels are indicated by ${ }^{* * *}, * *$ and ${ }^{*}$ respectively 


\subsection{Additional Regressions}

To check the robustness of our results, we present a few additional regressions. First of all, to negate the effect of variations at the extremes of the age range 20-35, we suggest relying only on observations that are increasingly close to the discontinuity point. We do so using the linear spline model and report the results in the second panel of table 3 . For instance, the second row shows the results for a " \pm 4 years" window (that is, for the age range 21-29). The smallest window we can use with the linear spline model is " \pm 2 years" since we need at least two observations on each side to identify separate regression lines (the $\mathrm{R} 2$ is equal to one in this case). Results are very robust to the age window used in the estimation, with employment rate effects (in ppt) in the range $[-7.9,-5.2]$ and hours effects in the range $[-2.8,-1.9]$. It is reassuring to see that the magnitude of these effects is not very different - and not actually statistically different - from those obtained with the 20-35 age window in the main regressions.

We also run local linear regressions for the main group (age 20-35) using age in months. These nonparametric estimates provide additional confidence in the robustness of the results obtained with the polynomial models. In the last panel of table 3, we simply report regressions obtained with a triangular kernel and a rectangular kernel for three different bandwidths corresponding to 1, 2 and 4 years. Estimates are slightly larger than - but not statistically different from - those obtained with the parametric linear spline model. They are much less precisely estimated due to the noise in age reported in months. A larger bandwidth decreases the variance because we include more observations and take the separate effect of months on outcomes into account (yet it should also increase the inaccuracy of the estimated effect since we move further away from the discontinuity).

\subsection{Control Groups}

We check the robustness of our regressions by inspecting the groups of people who are not affected by the RMI. Two obvious groups emerge. The first is the same target group of single male junior school dropouts aged 20-35, but observed in 1982, i.e., six years before the RMI was introduced. The second is the group of single mothers who are, by definition, eligible for the RMI at any age. Table 4 reveals a marked contrast between these groups and our group of interest. The treatment effect is insignificant for each control group, regardless of the functional form.

We see confirmation of these results upon looking at the graphs in figures 7 and 8 in the Appendix. It is quite clear that no significant discontinuity appears at age 25 for either group. In the first graph, we note that uneducated single men had a higher overall employment rate in 1982 than their counterparts in 1999. This is consistent with figure 2. For lone mothers, the employment-age profile is very smooth so that the absence of any discontinuity is very clear. The employment rates of these lone parents show a fast upward trend but remain low. This group is known to have very small (or negative) financial gains to work, possibly due to fixed costs of work such as childcare (Gurgand and Margolis, 2008). That is, the RMI effect is not necessarily absent for this group but may in fact exist at all ages and explain the 
Table 3: RD Estimates: Additional Regressions

\begin{tabular}{|c|c|c|c|c|}
\hline & \multicolumn{2}{|c|}{ Emp. Rate } & \multicolumn{2}{|c|}{ Weekly hours } \\
\hline Linear spline, with age window widths: & age in: years & quarters & years & quarters \\
\hline \multirow[t]{2}{*}{ \pm 5 years around 25} & $-0.052 * * *$ & $-0.058 * * *$ & $-1.953 * * *$ & $-2.214 * * *$ \\
\hline & $(0.012)$ & $(0.016)$ & $(0.446)$ & $(0.627)$ \\
\hline \multirow[t]{2}{*}{ \pm 4 years around 25} & $-0.060 * * *$ & $-0.069 * * *$ & $-2.146 * * *$ & $-2.504 * * *$ \\
\hline & $(0.009)$ & $(0.016)$ & $(0.345)$ & $(0.610)$ \\
\hline \multirow[t]{2}{*}{ \pm 3 years around 25} & $-0.065 * * *$ & $-0.072 * * *$ & $-2.259 * * *$ & $-2.551 * * *$ \\
\hline & $(0.011)$ & $(0.021)$ & $(0.487)$ & $(0.803)$ \\
\hline \pm 2 years around 25 & $-0.067(-)$ & $-0.079(-)$ & $-2.157(-)$ & $-2.804(-)$ \\
\hline Local linear regressions, with bandwidth: & age in: months & & months & \\
\hline \multirow[t]{2}{*}{24 months (triang. kernel) } & $-0.080 * *$ & & $-3.023 * *$ & \\
\hline & $(0.032)$ & & $(1.250)$ & \\
\hline \multirow[t]{2}{*}{12 months (rect. kernel) } & $-0.071 *$ & & $-2.983 *$ & \\
\hline & $(0.040)$ & & $(1.574)$ & \\
\hline \multirow[t]{2}{*}{24 months (rect. kernel) } & $-0.088 * * *$ & & $-3.193 * * *$ & \\
\hline & $(0.031)$ & & $(1.188)$ & \\
\hline \multirow[t]{2}{*}{48 months (rect. kernel) } & $-0.078 * * *$ & & $-2.935 * * *$ & \\
\hline & $(0.021)$ & & $(0.642)$ & \\
\hline
\end{tabular}

Note: statistical significance at the 1\%, 5\%, 10\% levels are indicated by ***,** and * respectively 
very low employment levels in figure 8 .

Table 4: Falsification Test: Comparing Alternative JS Dropout Groups

\begin{tabular}{lccc}
\hline \hline Specification for age & Single male 1999 & Single male 1982 & Lone mothers 1999 \\
\hline Mean emp. rate & 0.68 & 0.80 & 0.37 \\
& & & \\
Regression discontinuity estimates & -0.027 & 0.016 & -0.017 \\
Linear & $(0.018)$ & $(0.019)$ & $(0.013)$ \\
& $-0.067 * * *$ & -0.009 & -0.003 \\
Quadratic & $(0.013)$ & $(0.018)$ & $(0.014)$ \\
& $-0.065 * * *$ & -0.003 & 0.002 \\
Cubic & $(0.014)$ & $(0.021)$ & $(0.016)$ \\
& $-0.049 * * *$ & 0.006 & -0.013 \\
Linear spline & $(0.010)$ & $(0.018)$ & $(0.014)$ \\
& $-0.067 * * *$ & 0.010 & -0.004 \\
Quadratic spline & $(0.017)$ & $(0.023)$ & $(0.019)$ \\
&
\end{tabular}

Note: statistical significance at the $1 \%, 5 \%, 10 \%$ levels are indicated by $* * *, * *$ and $*$ respectively. Specifications with age in years.

\subsection{Broader Educational Groups}

We also look at single men aged 20-35 with higher educational levels than our group of interest. We expect that broadening the target group in this way may reveal whether or not the employment effect of the RMI is limited to junior school dropouts, as suggested by the first analysis based on the LFS above. Results are presented in table 5 .

First, it is not surprisingly to see that average employment levels for those with education are much higher than for the target group, possibly due to a number of effects. On the supply side, educated adults have larger financial incentives to work, as discussed in Section 2. They may also have unobserved characteristics that explain both higher educational achievement and a stronger attachment to the labor market. In addition, they have higher returns to seniority and hence higher (dynamic) incentives to stay in the labor market (cf., Beffy et al., 2006). On the demand side, those with a degree are possibly less at risk of being rationed out of the market because of the minimum wage; a degree may also protect them to some extent from other (frictional) unemployment.

Next, we expect the treatment effect to be smaller for higher educated men. This is due to the supply-side reasons suggested above (larger earnings prospects, unobserved heterogeneity, higher return to seniority). Also, part of the demand-side explanations above may result in higher job search costs for low educated individuals (discouraged workers). Results reported in table 5 show no significant treatment effect for educated workers. The lack of discontinuity at age 25 is particularly interesting for those with a vocational degree. We have seen in table 7 (Appendix) that their financial gains to work 
are on average not much larger than that of junior school dropouts. So we surmise that the role of unobserved characteristics and job search costs in explaining the inactivity trap is potentially large. This is reinforced by the observation that unemployment rates are much smaller for this group compared to junior school dropouts (cf., bottom rows of table 7). The policy implications of these results are discussed in the concluding section.

Table 5: Employment Effect: Broadening the Target Group to Higher Education Levels

\begin{tabular}{lcccc}
\hline \hline Specification for age & $\begin{array}{c}\text { Junior school } \\
\text { dropouts }\end{array}$ & Apprenticeship & Highschool & University degree \\
\hline Mean emp. rate & 0.68 & 0.84 & 0.88 & 0.92 \\
& & & & $0.011 *$ \\
Regression discontinuity estimates & -0.027 & 0.002 & 0.015 & $(0.006)$ \\
Linear & $(0.018)$ & $(0.007)$ & $(0.010)$ & -0.005 \\
& $-0.067 * * *$ & -0.004 & 0.001 & $(0.005)$ \\
Quadratic & $(0.013)$ & $(0.009)$ & $(0.011)$ & -0.006 \\
Cubic & $-0.065 * * *$ & -0.005 & 0.009 & $(0.004)$ \\
Linear spline & $(0.014)$ & $(0.010)$ & $(0.007)$ & 0.004 \\
& $-0.049 * * *$ & -0.002 & 0.005 & $(0.004)$ \\
Quadratic spline & $(0.010)$ & $(0.008)$ & $(0.006)$ & -0.002 \\
& $-0.067 * * *$ & -0.007 & 0.017 & $(0.004)$ \\
\hline
\end{tabular}

Note: statistical significance at the 1\%,5\%,10\% levels are indicated by ***,** and * respectively.

Estimates are based on age in years. Selected sample: single men without children.

\subsection{Testing Possible "Manipulation" Effects}

The question of sample selectivity, due to the fact that we consider only single men without children, is an issue if "manipulation" effects are possible. In our context, fertility decisions might be directly influenced by the generosity of social assistance transfers. That is, some people may decide to have children in order to become eligible for welfare assistance before $25 .^{22}$ It is reasonable to assume that this effect is relatively limited for single men. Table 8 in the Appendix shows that the proportion of single males with children (among junior school dropouts) is very small under age 25 , from $1 \%$ at age 20 to $7 \%$ at age 24 . For men in couples, however, we would like to check whether or not we observe an accelerated fertility rate below age 25 compared to the "normal" demographic trend. Another type of manipulation effect pertains to living arrangements with partner/children for those who take up the RMI.

\footnotetext{
${ }^{22}$ For France, Laroque and Salanié (2004) consider the fertility effect of a replacement income for women with two or more children (Allocation Parentale d'Education). There is an abundance of literature on the effects of the American welfare system on fertility, cohabitation and single motherhood. Most studies' estimates rely on variation in benefits (in particular the Aid to Families with Dependent Children, AFDC) over time and across US states to identify the welfare effect. Some find small significant effects (Schultz, 1994, Rosenzweig, 1999, Blau, 2004) while some find no effect at all (Moffitt, 1994, Hoynes, 1997).
} 
We argue that this potential bias concerns adults aged 25 and above only. Indeed, there is no incentive for an inactive couple with a child, where both adults are under age 25 , to declare different addresses. ${ }^{23}$ However, if the man turns 25 before the woman (of if both are at least 25), this couple would receive more if they declare that the man lives alone and the woman lives with the child (he would then receive EUR 454 and she would get EUR 682, cf. table 1), rather than declaring that they live as a couple with a child (they would only receive EUR 818 in this case). This type of manipulation implies that the change in the proportion of men living with a partner and children should be discontinuous at age 25 .

Unfortunately, it is difficult to find a control group that would indicate what the "normal" fertility or living arrangement patterns are. The best we could do with the available data was to perform a double comparison using year 1982 (no RMI) and educated groups (less sensitive to the RMI), as reported in figure 9 in the Appendix. We first observe that men tend to live with their partner and children earlier and at a higher rate in 1982 than in 1999. This is possibly due to a combination of higher fertility and lower probability of being single. Importantly, we observe that junior school dropouts under 25 have higher fertility levels than the educated group but that this is the case for both years. Hence results do not point to any specific fertility acceleration before 25. Figure 9 also shows that the slope of the curve for junior school dropouts 1999 does not change abruptly around the discontinuity point. This group (black lines) shows a flatter trend after age 24 compared to the educated group (grey lines), but this was already the case in 1982; for both years, educated men tend to have less children in their early 20s but catch up after age 27.

There is arguably a more direct and intuitive test of whether manipulation effects change the size of the selected sample in a discontinuous way on both sides of the cutoff point. It consists of examining the density of the forcing variable itself at the discontinuity point. A jump in the density at the threshold would suggest some degree of sorting around this point and would call into question the exchangeability of observations on either side of it, as well as the validity of the RD approach. ${ }^{24}$ First of all, visual inspection in figure 10 does not suggest any such discontinuity in age. We also implement the test suggested by McCrary (2008) to check the continuity of age at the threshold using only the closest observations. To do so, we run local linear regressions of the fraction of men in each age group below and above the discontinuity point, checking whether the fraction of men predicted to be at age 25 is the same for the two regressions. We use a triangular kernel, i.e., weights on age groups in the local linear regressions linearly decline from one at the discontinuity point to zero $\mathrm{X}$ years/quarters away from this point. We obtain standard errors of the test by bootstrapping. We cannot reject the null that the density of age is the same just below and just above the discontinuity point. For bandwidths $X=2,3$ and 5 years, the p-values are $0.57,0.35$ and 0.31 respectively. For $X=8,12$ and 20 quarters, the p-values are $0.60,0.42$ and 0.35 respectively.

\footnotetext{
${ }^{23} \mathrm{~A}$ couple is eligible if at least one of the partners is aged 25 or over. The age of the other person holds no relevance for the amount received, i.e, the couple still receives more than a single.

${ }^{24}$ Note that this test also accounts for direct manipulation of the forcing variable in the unlikely event that people can cheat on their age when claiming the RMI.
} 


\subsection{Broader Demographic Groups}

We finally examine broader demographic groups, still focusing on junior school dropouts. In figure 11 in the Appendix, we compare the trends in employment rates for single childless men, all childless men (single and in couples) and all men. Estimates of the treatment effects for each group are reported in table 6. Looking at broader groups partly solves the selection problem but, at the same time, the employment effect is expected to be smaller.

Figure 11 confirms that men in couples are less sensitive to the treatment (for "all childless men", the effect is significant only with age in quarters, cf. table 6). Several explanations may account for this. In particular, men in couples may rely financially on their partner (or on their partner's family). They may be eligible for the RMI when their partner turns 25 so that we are no longer in the case of a sharp discontinuity. More generally, the joint labor supply decision in couples is complex so that this broader group does not lend itself to a clear-cut experiment as was the case for singles. In the broadest group ("all men"), around three-quarters of the men aged 25-35 are in couples and more than half have children (and are thereby unaffected by the RMI age condition). Thus the strong effect for single males is diluted in this larger group; unsurprisingly, in figure 11, there is no longer a drop in the employment curve at 25 but simply a flattening of the curve at that age. ${ }^{25}$

Interestingly, comparisons with other demographic groups help us to understand the pattern obtained for the core group. Noteworthy was the fact that the employment rate for childless single men trends upwards as a function of age but then flattens out after the discontinuity. As revealed by figure 11, this is also the case for the broader group of men without children but in sharp contrast to the broadest group ("all men") including men with children. Therefore, this trend seems to be driven by the fact that men without children are negatively selected in terms of their labor market prospects and that the magnitude of the bias increases as a function of age (see Lemieux and Milligan, 2008, for similar findings). This result was already present in 1982 for junior school dropouts (cf. figure 7) and is not limited to this group: the employment trend of childless men with a vocational degree, highschool diploma or a university degree is also very flat in this age range (graphs available upon request).

\section{Conclusion}

This study exploits a unique feature of the French guaranteed minimum income, namely that persons aged under 25 are not eligible for it. We find strong evidence that the transfer program significantly reduces the employment rate of single male junior school dropouts. The effect has been quantified: around $7-10 \%$ of the target group appears to withdraw from the labor market upon becoming eligible

\footnotetext{
${ }^{25}$ We have also run on micro data (using the broad sample of all men) a version of model (1) augmented with educational and demographic dummies and their interaction with the treatment variable. These estimations confirm that the treatment is significant for childless single men only. These additional results are available upon request.
} 
Table 6: Employment Effect: Broadening the Demographic Groups

\begin{tabular}{|c|c|c|c|c|c|c|c|c|}
\hline \multirow{2}{*}{ Specification for age } & \multicolumn{2}{|c|}{ Childless single men } & \multicolumn{2}{|c|}{ All single men (inc. lone fathers) } & \multicolumn{2}{|c|}{ All childless men (incl. in couple) } & \multicolumn{2}{|c|}{ All men } \\
\hline & age in: years & quarters & years & quarters & years & quarters & years & quarters \\
\hline \multicolumn{9}{|l|}{ Statistics } \\
\hline Proportion of all men & \multicolumn{2}{|c|}{0.20} & \multicolumn{2}{|c|}{0.21} & \multicolumn{2}{|c|}{0.41} & & \\
\hline Mean emp. rate & \multicolumn{2}{|c|}{0.68} & \multicolumn{2}{|c|}{0.68} & \multicolumn{2}{|c|}{0.74} & \multicolumn{2}{|c|}{0.79} \\
\hline \multicolumn{9}{|c|}{ Regression discontinuity estimates } \\
\hline \multirow[t]{2}{*}{ Linear } & -0.027 & $-0.028 * *$ & -0.021 & -0.022 & 0.035 & $0.034 * *$ & $0.040 *$ & $0.039 * * *$ \\
\hline & $(0.018)$ & $(0.014)$ & $(0.018)$ & $(0.013)$ & $(0.030)$ & $(0.016)$ & $(0.022)$ & $(0.012)$ \\
\hline \multirow[t]{2}{*}{ Quadratic } & $-0.067 * * *$ & $-0.069 * * *$ & $-0.062 * * *$ & $-0.064 * * *$ & $-0.035 *$ & $-0.036 * * *$ & -0.019 & $-0.019 *$ \\
\hline & $(0.013)$ & $(0.015)$ & $(0.013)$ & $(0.015)$ & $(0.018)$ & $(0.012)$ & $(0.013)$ & $(0.010)$ \\
\hline \multirow[t]{2}{*}{ Cubic } & $-0.065 * * *$ & $-0.067 * * *$ & $-0.057 * * *$ & $-0.060 * * *$ & -0.028 & $-0.029 * *$ & -0.016 & $-0.016 *$ \\
\hline & $(0.014)$ & $(0.016)$ & $(0.014)$ & $(0.015)$ & $(0.018)$ & (0.013) & $(0.013)$ & $(0.010)$ \\
\hline \multirow[t]{2}{*}{ Linear spline } & $-0.049 * * *$ & $-0.058 * * *$ & $-0.044 * * *$ & $-0.053 * * *$ & -0.003 & $-0.018 *$ & 0.010 & -0.001 \\
\hline & $(0.010)$ & $(0.014)$ & $(0.009)$ & $(0.013)$ & $(0.011)$ & $(0.010)$ & $(0.012)$ & $(0.009)$ \\
\hline \multirow[t]{2}{*}{ Quadratic spline } & $-0.067 * * *$ & $-0.068 * * *$ & $-0.059 * * *$ & $-0.060 * * *$ & -0.024 & $-0.025 *$ & -0.015 & -0.015 \\
\hline & $(0.017)$ & $(0.018)$ & $(0.017)$ & $(0.017)$ & $(0.023)$ & $(0.014)$ & $(0.015)$ & $(0.011)$ \\
\hline
\end{tabular}

for the RMI. ${ }^{26}$ The treatment effect is insignificant for those not affected by the 25 year-old threshold (lone parents, uneducated men in 1982) and those less likely to be affected by small gains to work (higher education groups). In a broader perspective, our results confirm that financial incentives do not only concern married women and single mothers - as often reported in the empirical literature - but also uneducated single men. This is all the more important as this group represents the core of welfare dependents in France.

One would like to extrapolate these results to quantify the overall proportion of RMIsts affected by supply-side effects. However, the treatment effect is identified only for single men aged around 25 and might not generalize to other age and demographic groups. ${ }^{27}$ Nonetheless, we note that the group concerned by inactivity traps (junior school dropouts) is strongly over-represented in the population of RMI recipients at all ages. For other demographic groups like single mothers, the effect may be even stronger than for single males. This is demonstrated by the very low employment rates of single mothers reported in this paper and by additional evidence in Piketty $(1998,2005) .^{28}$

\footnotetext{
${ }^{26}$ Interestingly, both the magnitudes of the financial effect on disposable income and of the labor market response are comparable to what is found for Québec in Lemieux and Milligan (2008).

${ }^{27}$ In addition, the effect measured at 25 is possibly underestimated. Indeed, as discussed in section 2, there is a potential decrease in intrahousehold transfers to children when they reach 25, which may partly offset the negative employment effect of the RMI. Also, the supply-side effect may concern a larger group than those who stop work at 25 to take up the RMI, and in particular those who did not work prior to the discontinuity, possibly relying on unemployment benefits, family solidarities or informal labor markets.

${ }^{28}$ For the group of single women, RD estimates are significant but smaller compared to what we found for males (results
} 
Because of these obstacles to extrapolation, we simply put some of our results in the perspective of a more general policy context. It is interesting to notice that policy makers in France have focused their attention on measures aimed at increasing financial incentives to work. Inspired by the example of family tax credits in the US and the UK, they have adopted an earned income tax credit (Prime pour l'Emploi, PPE) in 2001. This policy has been essentially designed as an individualized tax credit and hence covers a large group of workers (around 8 million, i.e., $30 \%$ of the labor force); as a result, redistributed amounts are small and incentive effects are suspected to be weak.$^{29}$ Yet, our results suggest that inactivity traps exist but are probably confined to those with low education levels (or facing high costs of work, like single mothers). This calls for a better targeting of 'make work pay' policies. ${ }^{30}$ Also, we show that single men with apprenticeships do not seem to be affected by the RMI. Interestingly, this group has only marginally higher expected wages than junior school dropouts. Thus the question remains about whether stronger attachment to the labor market for this group is provided by the degree itself or reflects self-selection and unobserved characteristics. In the former case, targeted policies aimed at helping uneducated workers to build up their human capital, increase their potential market wage and reduce job search costs might prove effective.

A clear limitation of the present study is that we have left aside all redistributive aspects. Youth poverty is a particularly acute problem in France. As explained in the text, young workers are excluded from the labor market and, at the same time, are not covered by either UB or the RMI. This explains the high poverty rate among 18-24 year olds: around $10 \%$ are under the $50 \%$ median poverty line (official definition in France) compared to $5.5 \%$ for the 25-30 year olds and 6.3\% for the overall population. Further research should evaluate the implication of limited access to social assistance for young workers and the relationship between labor market achievement and poverty among the young. A recent report to the Prime Minister advocates the extension of the RMI/RSA to 18-24 year olds (Cahuc et al., 2008). Commentary made in this report nonetheless points out the risk of a negative impact on employment in this age group.

Several aspects are not discussed in the paper but are worth investigating and relevant for the poverty issue. The first is the possibility of receiving income from informal sector activities. This may further decrease the differential between financial returns to "official" work and welfare payments, and hence exacerbate the disincentive effect due to the RMI. In this case, it would be interesting to verify if the target group characterized in the present study does indeed increase its participation in the shadow labor market at age 25. Fortin et al. (1994) actually show that high implicit marginal tax rates associated with social programmes have an important effect on the decision to work in the shadow economy. Another point relates to dynamic aspects. We have simply considered the static participation effect of the RMI.

\footnotetext{
available upon request). As argued previously, however, selection problems are more likely to arise for this population.

${ }^{29}$ Nonetheless, Stancanelli (2008) finds significant employment effects using a difference-in-different approach.

${ }^{30}$ Note that in 2009, a new system known as Revenue de Solidarité Active (RSA) will replace the RMI by introducing the possibility of permanently cumulating earnings and transfers. Means-tested on household income, this scheme should be better targeted at low-income families.
} 
The program may also affect the intertemporal allocation of labor supply. ${ }^{31}$ Yet it seems unlikely that those who anticipate leaving the labor market at age 25 work more in the years before. On the contrary, it is possible that the RMI encourages younger workers to linger in precarious activities while "waiting" for the RMI, as suggested by the significant decrease in the proportion of temporary contracts at age 25 . If the underground economy is an option, labor supply is not zero after 24 in any case. Finally, margins other than labor supply may be affected by the RMI and, in particular, training decisions. ${ }^{32}$

\section{References}

[1] Aaberge, R., Colombino, U. and Strom, S. (1999): "Labour Supply in Italy: An Empirical Analysis of Joint Household Decisions, with Taxes and Quantity Constraints", Journal of Applied Econometrics, $14(4), 403-422$

[2] Abowd, J., F. Kramarz, T. Lemieux, D. Margolis (1999): "Minimum Wage and Youth Employment in France and the United-States", in Youth Employment and Joblessness in Advanced Countries, D. Blanchflower et R. Freeman, eds.,University of Chicago Press, 427-472

[3] Adda, J., Dustmann, C., Meghir, C and Robin, J-M. (2006), "Career Progression and Formal versus On-the-Job Training", IZA working Paper

[4] Beffy, M., M. Buchinsky, D. Fougère, T. Kamionka, F. Kramarz (2006): "The Returns to Seniority in France (and Why Are They Lower than in the United States?)", IZA DP No. 1935

[5] Blau, F., L. Kahn and J. Waldfogel (2004): "The Impact of Welfare Benefits on Single Motherhood and Headship of Young Women. Evidence from the Census", Journal of Human Resources 39(2): 382-404.

[6] Blundell, R. and T. MaCurdy (1999), "Labor Supply: A Review of Alternative Approaches," in Handbook of Labor Economics, Vol. 3A. Ashenfelter and Card eds.

[7] Blundell, R.W., A. Duncan, J. McCrae and C. Meghir (2000): "The Labour Market Impact of the Working Families' Tax Credit", Fiscal Studies, 21, 1, 75-103.

[8] Bourguignon F. (1997), Fiscalité et redistribution, Conseil d'Analyse Economique report, La Documentation Française.

\footnotetext{
${ }^{31}$ To estimate intertemporal labor supply elasticities, much of the literature has used age and education related variables as instruments for lifecycle wage changes; yet these measures are potentially correlated with changes in tastes. Mulligan (1999) exploits the anticipated change in net-of-benefit wage corresponding to the end of eligibility for the AFDC benefit when the youngest child reaches the age of 18. A similar exercise could be suggested in our case. Yet, census data do not contain information on wages to allow the estimation of Frisch elasticites.

${ }^{32}$ Adda et al. (2006) suggest a sophisticated dynamic model with multiple decision margins including education, on-thejob training and employment decisions.
} 
[9] Cahuc, P., G. Cette and A. Zylberberg (2008): "Salaire minimum et bas revenus : comment concilier justice sociale et efficacité économique ?", Conseil d'Analyse Economique report, La Documentation Française.

[10] Fan, J. and I. Gijbels (1996), Local Polynomial Modelling and Its Applications, Chapman and Hall, London.

[11] Fortin, B., P. Fréchette and T. Lemieux (1994): "The Effect of Taxes on Labor Supply in the Underground Economy", American Economic Review, 84, 231-254

[12] Fortin, B., G. Lacroix and S. Drolet (2004): "Welfare benefits and the duration of welfare spells: evidence from a natural experiment in Canada", Journal of Public Economics, 88, 1495-1520

[13] Fougère, D., F. Kramarz, T. Magnac (2000): "Youth Employment Policies in France", European Economic Review, 44, 928-942

[14] Guillemot, D., P. Pétour and H. Zajdela (2002): "Trappe à chômage ou trappe à pauvreté: Quel est le sort des allocataires du RMI ?", Revue économique, 53 (6), 1235-1252

[15] Gurgand M. and D. Margolis (2008): "Does work pay in France? Monetary incentives, hours constraints, and the guaranteed minimum income", Journal of Public Economics, 92,1669-1697

[16] Hagneré C. and A.Trannoy (2001): "L'impact conjugué de trois ans de réforme sur les trappes à inactivité", Economie et Statistique, 346-347, 6-7, 161-185

[17] Hahn, J., van der Klaauw, W., Todd, P. (2001): "Identification and estimation of treatment effects with a regression-discontinuity design", Econometrica 69, 201-209.

[18] Hoynes, H. W. (1997): "Does Welfare Play Any Role in Female Headship Decisions?", Journal of Public Economics 65: 89-118.

[19] Imbens, G. and T. Lemieux (2008): "Regression Discontinuity Designs: A Guide to Practice", Journal of Econometrics, 142 (2), 615-635.

[20] Laroque G. and B.Salanié (2002): "Labour market institutions and employment in France", Journal of Applied Econometrics, 17, 25-48

[21] Laroque G. and B.Salanié (2004): "Fertility and Financial Incentives in France", CESIfo Economic Studies, 50(3), 423-450,

[22] Lee, D.S. (2008): "Randomized experiments from non-random selection in U.S. House elections", Journal of Econometrics, 142(2), 675-697

[23] Lee, D.S. and Card, D. (2008): "Regression discontinuity inference with specification error", Journal of Econometrics, 142(2), 655-674 
[24] Lemieux, T. and K. Milligan (2008): "Incentive effects of social assistance: a regression discontinuity approach", Journal of Econometrics, 142(2), 807-828

[25] McCrary, J. (2008): "Manipulation of the running variable in the regression discontinuity design: a density test", Journal of Econometrics, 142(2), 698-714

[26] Meghir, C., and D. Phillips (2008): "Labour Supply and Taxes", forthcoming in The Mirrlees Review: Reforming the Tax System for the 21st Century

[27] Moffitt, R. (1994): "Welfare Effects on Female Headship with Area Effects." Journal of Human Resources 29: 621-636.

[28] Mood, C.M. (2004): "Social Influence Effects on Social Assistance Recipiency", Acta Sociologica, 47: $235-251$

[29] Mulligan, C. B. (1999): "Substitution over Time: Another Look at Lifecycle Labor Supply", In B. S. Bernanke and J. J. Rotemberg, eds. NBER Macroeconomics Annual 1998, Volume 13, Cambridge and London: MIT Press, pp. 75-134

[30] Piketty, T. (1998): "L'impact des incitations financières au travail sur les comportements individuels: une estimation pour le cas français.", Economie et Prévision 132-133, 1-35.

[31] Piketty, T. (2005): "L'impact de l'allocation parentale d'éducation sur l'activité feminine et la fécondité en France, 1982-2002". In: Lefevre, Cécile (Ed.), Histoires de familles, histoires familiales, Les Cahiers de l'INED, vol. 156, pp. 79-109.

[32] Rosenzweig, M. R. (1999): "Welfare, Marital Prospects, and Nonmarital Childbearing", Journal of Political Economy 107(6): S3-S32

[33] Schultz, P. T. (1994): "Marital Status and Fertility in the United States. Welfare and Labor Market Effects." Journal of Human Resources 29: 637-669.

[34] Stancanelli, E. (2008): "Evaluating the impact of the French tax credit on the employment rate of women", Journal of Public Economics, 92, 10-11, 2036-47.

[35] Terracol, A. (2002): "Analysing the Take-Up of Means-Tested Benefits in France", mimeo, Université Paris I-Panthéon-Sorbonne.

[36] Terracol, A. (2008): "Guaranteed minimum income and unemployment duration in France", Labour Economics, 16(2), 171-182 


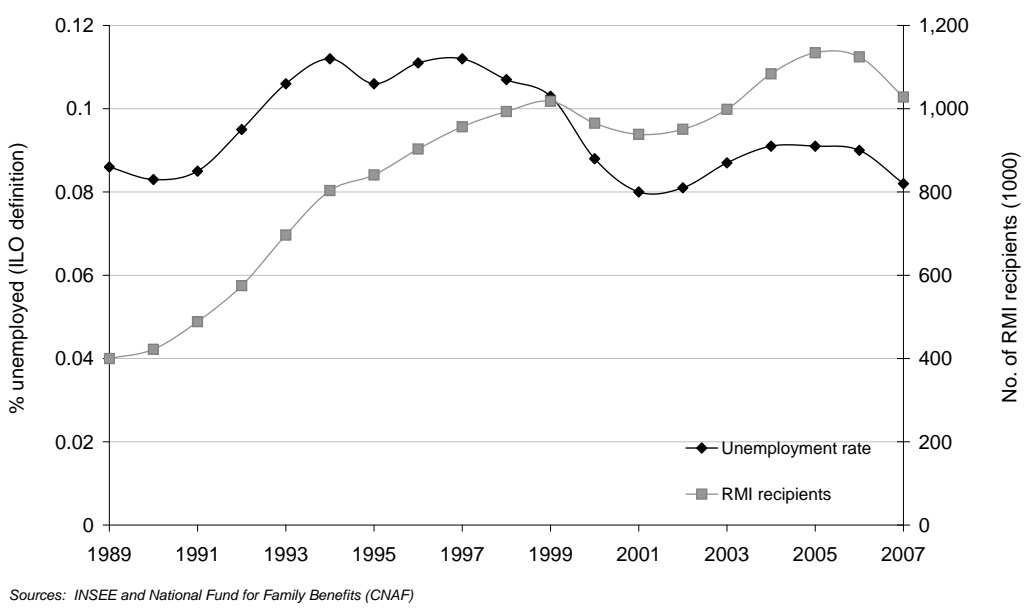

Figure 6: Trend in Unemployment and Welfare Assistance

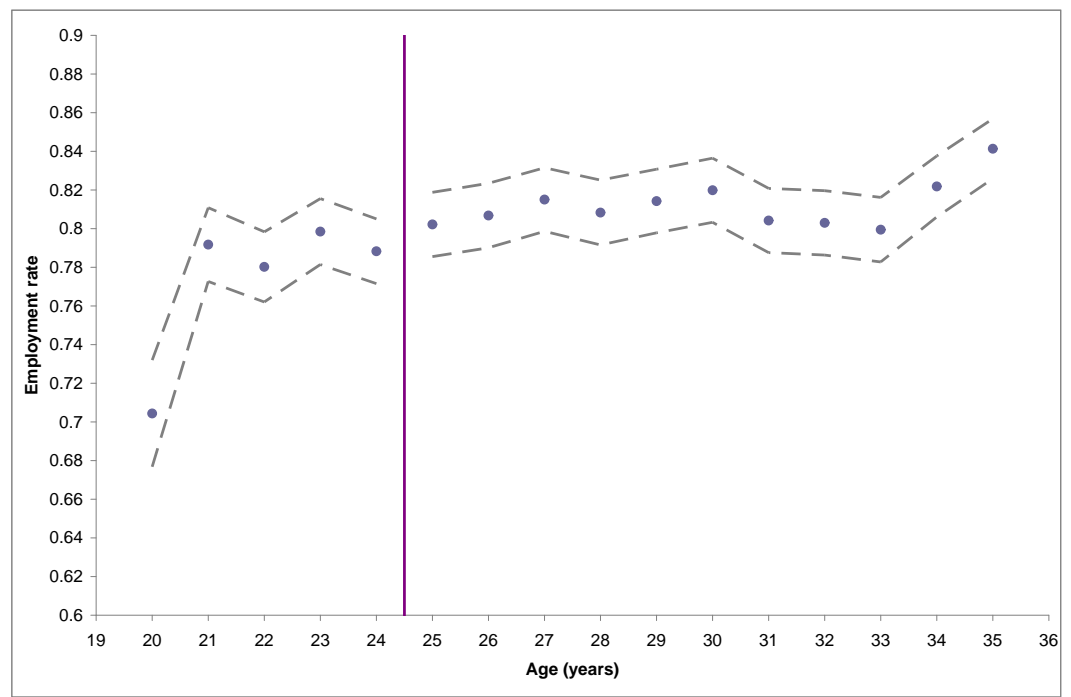

Figure 7: Employment rate of Single Male JS Dropouts (Census 1982) 


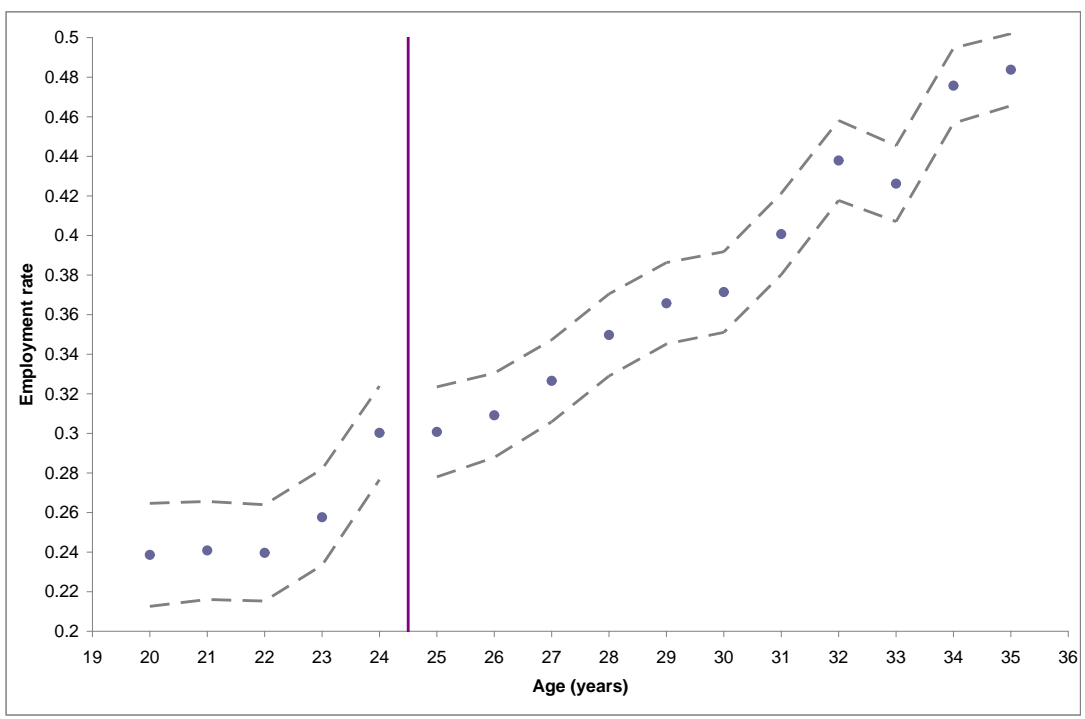

Figure 8: Employment Rate of Lone Parents, JS Dropouts (Census 1999)

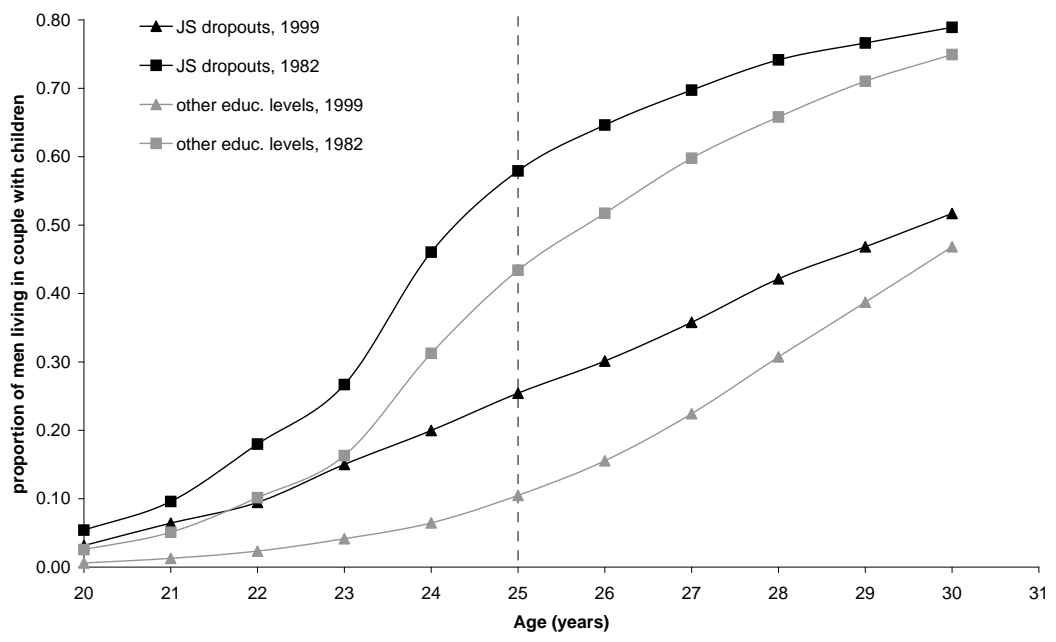

Figure 9: Proportion of Men Living in Couples with Children 

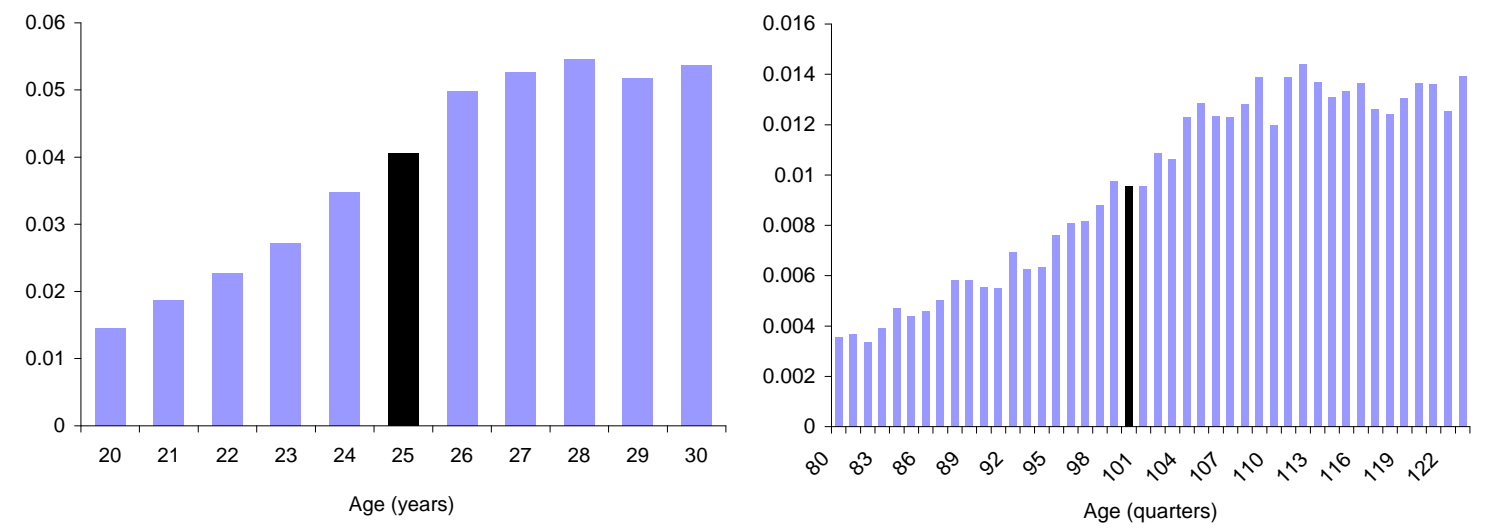

Figure 10: Inspecting Discontinuity in the Forcing Variable

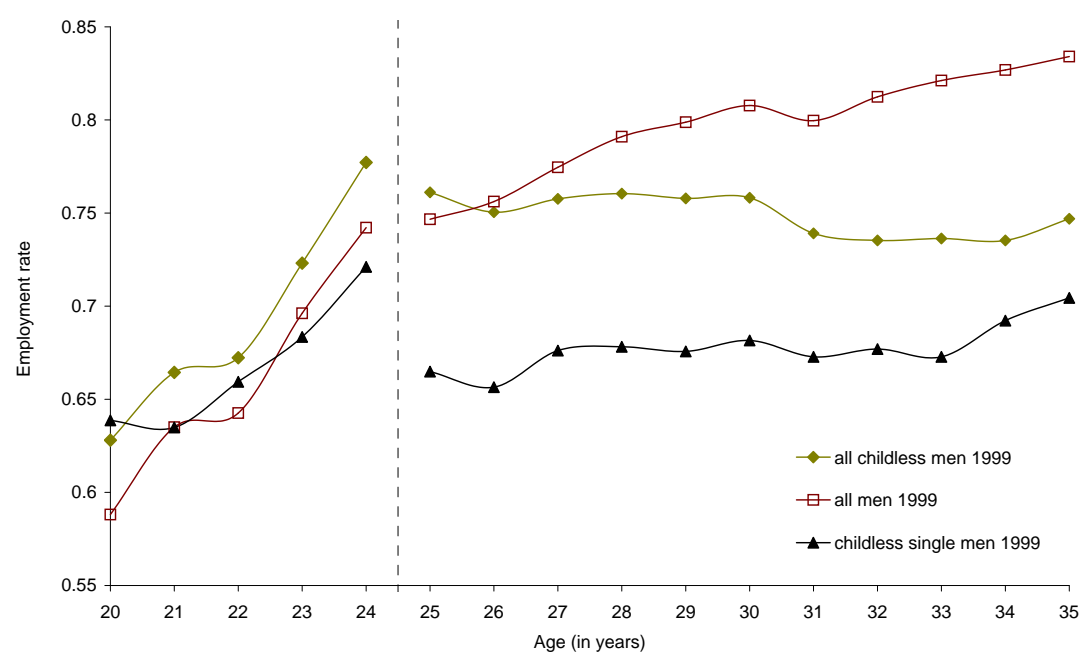

Figure 11: Employment Rate for All Male JS Dropouts 
Table 7: Financial Incentives by Educational Group (Males)

\begin{tabular}{|c|c|c|c|c|c|c|}
\hline & $\begin{array}{l}\text { junior school } \\
\text { dropout }\end{array}$ & $\begin{array}{l}\text { apprenctice- } \\
\text { ship }\end{array}$ & highschool & $\begin{array}{c}\text { 2-year } \\
\text { university } \\
\text { degree }\end{array}$ & $\begin{array}{l}\text { higher } \\
\text { degree }\end{array}$ & All \\
\hline \multicolumn{7}{|l|}{ Median hourly wage } \\
\hline in Euro & 6.6 & 7.0 & 7.5 & 9.0 & 12.0 & 7.6 \\
\hline in prop. of the minimum wage & 1.06 & 1.13 & 1.21 & 1.46 & 1.94 & 1.22 \\
\hline \multicolumn{7}{|l|}{ Average working time (hours/week) } \\
\hline for participants & 37.9 & 39.0 & 39.0 & 38.9 & 39.3 & 39.0 \\
\hline incl. zeros & 26.3 & 29.3 & 23.7 & 27.5 & 26.9 & 27.7 \\
\hline \multicolumn{7}{|l|}{ Relative financial gain to work* } \\
\hline full time & 0.63 & 0.70 & 0.74 & 0.99 & 1.58 & 0.75 \\
\hline part time & 0.04 & 0.08 & 0.13 & 0.27 & 0.55 & 0.13 \\
\hline Distribution (\%) - all & 0.22 & 0.37 & 0.13 & 0.11 & 0.10 & \\
\hline Distribution (\%) - RMI recipients & 0.52 & 0.22 & 0.08 & 0.05 & 0.07 & \\
\hline Unemployment rate (seniority $<5$ years) & 41.8 & 17.6 & 12.6 & 8.7 & & 15.6 \\
\hline Unemployment rate (seniority btw 5 and 10 years) & 25.9 & 11.7 & 5.8 & 4.2 & & 9.3 \\
\hline
\end{tabular}

Table 8: Sample Composition, All Men

\begin{tabular}{|c|c|c|c|c|c|c|c|}
\hline \multirow[b]{3}{*}{ Age } & \multicolumn{2}{|c|}{ All men 1999} & \multicolumn{4}{|c|}{ JS dropout 1999} & \\
\hline & & & \multicolumn{2}{|c|}{ All men 1999} & \multicolumn{3}{|c|}{ Single men 1999} \\
\hline & Cell size & $\%$ JS dropouts & Cell size & $\% \mathrm{w} /$ children & Cell size & $\% \mathrm{w} /$ children & $\% \mathrm{w} /$ parents \\
\hline 20 & 75,788 & 0.107 & 8,106 & 0.033 & 7,421 & 0.001 & 0.903 \\
\hline 21 & 75,835 & 0.096 & 7,278 & 0.065 & 6,157 & 0.001 & 0.870 \\
\hline 22 & 74,636 & 0.094 & 7,038 & 0.097 & 5,432 & 0.003 & 0.826 \\
\hline 23 & 74,550 & 0.100 & 7,462 & 0.153 & 5,059 & 0.005 & 0.786 \\
\hline 24 & 83,162 & 0.104 & 8,657 & 0.204 & 5,110 & 0.007 & 0.734 \\
\hline 25 & 88,047 & 0.111 & 9,774 & 0.260 & 5,138 & 0.010 & 0.689 \\
\hline 26 & 96,615 & 0.119 & 11,538 & 0.307 & 5,410 & 0.013 & 0.627 \\
\hline 27 & 98,602 & 0.127 & 12,515 & 0.363 & 5,314 & 0.013 & 0.579 \\
\hline 28 & 99,451 & 0.138 & 13,710 & 0.428 & 5,246 & 0.018 & 0.540 \\
\hline 29 & 97,550 & 0.141 & 13,733 & 0.475 & 4,767 & 0.021 & 0.506 \\
\hline 30 & 97,539 & 0.146 & 14,244 & 0.525 & 4,641 & 0.024 & 0.478 \\
\hline 31 & 98,037 & 0.147 & 14,381 & 0.565 & 4,414 & 0.029 & 0.449 \\
\hline 32 & 100,316 & 0.152 & 15,222 & 0.597 & 4,329 & 0.033 & 0.413 \\
\hline 33 & 102,512 & 0.157 & 16,103 & 0.618 & 4,497 & 0.039 & 0.395 \\
\hline 34 & 104,110 & 0.159 & 16,583 & 0.639 & 4,453 & 0.042 & 0.365 \\
\hline 35 & 105,396 & 0.160 & 16,899 & 0.655 & 4,366 & 0.047 & 0.347 \\
\hline
\end{tabular}

Note: These descriptive statistics are based on the French Census data covering 1/4 of the population. 